\title{
Removal of arsenate using graphene oxide- iron modified clinoptilolite-based composites: adsorption kinetic and column study
}

\author{
Meltem Bilici Baskan ${ }^{1 *}$ (D) and Seçil Hadimlioglu²
}

\begin{abstract}
In this study, graphene oxide (GO), iron modified clinoptilolite (FeZ), and composites of GO-FeZ (GOFeZA and GOFeZB) were synthesized and characterized using SEM, EDS, XRF, FTIR, and $\mathrm{pH}_{\mathrm{pzc}}$. The arsenate uptake on composites of GOFeZA and GOFeZB was examined by both kinetic and column studies. The adsorption capacity increases with the increase of the initial arsenate concentration at equilibrium for both composites. At the initial arsenate concentration of $450 \mu \mathrm{g} / \mathrm{L}$, the arsenate adsorption on GOFeZA and GOFeZB was 557.86 and $554.64 \mu \mathrm{g} / \mathrm{g}$, respectively. Arsenate adsorption on both composites showed good compatibility with the pseudo second order kinetic model. The adsorption process was explained by the surface complexation or ion exchange and electrostatic attraction between GOFeZA or GOFeZB and arsenate ions in the aqueous solution due to the relatively low equilibrium time and fairly rapid adsorption of arsenate at the beginning of the process. The adsorption mechanism was confirmed by characterization studies performed after arsenate was loaded onto the composites. The fixed-bed column experiments showed that the increasing the flow rate of the arsenate solution through the column resulted in a decrease in empty bed contact time, breakthrough time, and volume of treated water. As a result of the continuous operation column study with regenerated GOFeZA, it was demonstrated that the regenerated GOFeZA has lower breakthrough time and volume of treated water compared to fresh GOFeZA.
\end{abstract}

Keywords: Arsenate removal, Fixed-bed column study, Kinetic study, Graphene oxide, Clinoptilolite, Graphenebased composites

\section{Introduction}

Among the toxic elements, arsenic is one of the most abundant and hazardous pollutants in the natural environment. Although arsenic is found in air, water, many kinds of rock, soil, plant, and living tissues in general, the occurrence of arsenic in groundwater is a great and critical threat around the world (Dhoble et al. 2017; Pang et al. 2020). Despite the arsenic contamination in the groundwater of many countries in the various parts

\footnotetext{
* Correspondence: mbilici@pau.edu.tr

'Department of Environmental Engineering, Pamukkale University, 20160 Denizli, Turkey

Full list of author information is available at the end of the article
}

of the world being generally caused by natural sources such as the erosion of rocks and the dissolutionprecipitation of minerals, some anthropogenic activities such as mining, pharmaceutical industry, and the use of arsenic-containing fertilizers and pesticides in the agriculture also contribute to arsenic pollution (Wu et al. 2018; Luo et al. 2013; Kundu et al. 2004). Groundwater arsenic pollution is a worldwide problem that poses a health risk to millions of people in the countries such as Bangladesh, Vietnam, Indian, Turkey, the USA, and West Africa (Bretzler et al. 2020; Yoon et al. 2017; Bilici Baskan and Pala 2010). Consumption of groundwater containing a high concentration of arsenic causes fatal

\section{Springer Open}

(-) The Author(s). 2021 Open Access This article is licensed under a Creative Commons Attribution 4.0 International License, which permits use, sharing, adaptation, distribution and reproduction in any medium or format, as long as you give appropriate credit to the original author(s) and the source, provide a link to the Creative Commons licence, and indicate if changes were made. The images or other third party material in this article are included in the article's Creative Commons licence, unless indicated otherwise in a credit line to the material. If material is not included in the article's Creative Commons licence and your intended use is not permitted by statutory regulation or exceeds the permitted use, you will need to obtain permission directly from the copyright holder. To view a copy of this licence, visit http://creativecommons.org/licenses/by/4.0/. 
effects, while long-term use of water with low arsenic concentration can cause serious health problems such as different types of cancer and damage to various organs (Yin et al. 2017; Soni and Shukla 2019; Guo et al. 2015). In order to prevent these health problems, the guideline on arsenic concentration in drinking water has become gradually stricter over the last decades. As a result of this, many countries have set the maximum allowable arsenic concentration in drinking water to $10 \mu \mathrm{g} / \mathrm{L}$ adopted by the World Health Organization (WHO) and US Environmental Protection Agency (Wu et al. 2018; Cortes-Arriagada and Toro-Labbe 2016; Zhu et al. 2018). Therefore, researches on the use of more effective and economical methods or materials for removing arsenic from water are very important and necessary.

Arsenic exists in various forms in the environment, but in the aquatic environment it is mainly found in inorganic form as trivalent arsenite (As(III)) and pentavalent arsenate $(\mathrm{As}(\mathrm{V}))$ (Soni and Shukla 2019; Luo et al. 2013). Both species are non-biodegradable, highly toxic, and accumulate along the food chain. However, As(III) is 60 times more toxic than $\mathrm{As}(\mathrm{V})$ owing to its cellular uptake (Dhoble et al. 2017; Smedley and Kinniburgh 2002). Since $\mathrm{As}(\mathrm{III})$ is in the form of uncharged $\mathrm{H}_{3} \mathrm{AsO}_{3}$ in the $\mathrm{pH}$ range of $6-9$, where natural waters are most common, it can be removed from water much more difficult and with a lower efficiency than $\mathrm{As}(\mathrm{V})$. Therefore, oxidation of $\mathrm{As}(\mathrm{III})$ to $\mathrm{As}(\mathrm{V})$ takes place as a pretreatment process in most of the methods used for arsenic removal (Weerasundara et al. 2021; Amen et al. 2020). Many methods such as coagulation (Bora et al. 2016; Pallier et al. 2010), electrochemical processes (Goren and Kobya 2021; Kobya et al. 2020), ion exchange (Lee et al. 2017; Urbano et al. 2012), membrane filtration (Nguyen et al. 2009; Schmidt et al. 2016), and adsorption (Das et al. 2020) are used for removing arsenic from water in order to prevent the toxic effect on living forms and adverse effects on human health caused by arsenic in water resources. Among these methods, adsorption has attracted more attention due to its ease of operation, low cost, sustainability, efficiency, low waste generation and low energy requirement (Weerasundara et al. 2021; Amen et al. 2020). Many different natural and synthetic adsorbents have been tried to remove arsenic from water including industrial and agricultural wastes (Mohan and Pittman Jr 2007), Fe-Mn binary oxides (Zheng et al. 2020), fly ash (Ochedi et al. 2020), chitosan (Kloster et al. 2020), activated carbon (Hashim et al. 2019), and activated alumina (Tripathy and Raichur 2008). In recent years, zeolites have been used to remove many pollutants such as arsenic from water and wastewater due to their high surface area, easy availability, and low cost (Figueiredo and Quintelas 2014; Asere et al. 2019). However, zeolites are modified using various metals or materials, as they are not effective in removing inorganic arsenate oxyanions from water due to their surface characteristics (Simsek et al. 2013; Li et al. 2019). In this study, clinoptilolite, one of the most common type of zeolite and naturally abundant in Turkey, was used for arsenate adsorption by modifying the surface with the iron to increase its anion adsorption capacity.

In recent years, graphene oxide $(\mathrm{GO})$ and reduced graphene oxide $(\mathrm{rGO})$ are evaluated as promising new materials for arsenic removal from waters and wastewater due to their high thermal conductivity, mechanical stability, high surface area, and surface functional groups that provide a very good support for effective different compounds in arsenic adsorption (Wang et al. 2013; Wu et al. 2018). Graphene-based composite materials have found great approval in many environmental remediation applications, notably their use as adsorbents for the purification of water (Soni and Shukla 2019). Many researchers used GO-based composite materials such as GO-copper ferrite (Wu et al. 2018), GO-lanthanum fluoride (Lingamdinne et al. 2019), GO-iron oxide (Su et al. 2017), GO-ferric hydroxide (Zhang et al. 2010), and GO-magnetite (Yoon et al. 2016) to remove arsenic from water. However, there are only a few studies on the synthesis of GO-based composite materials using zeolite and its use for arsenic removal from waters. Khatamian et al. (2017) synthesized composite of GO-Cu exchanged zeolite for arsenate adsorption from aqueous solutions. This material was able to reduce the $100 \mu \mathrm{g} / \mathrm{L}$ arsenate concentration to less than $10 \mu \mathrm{g} / \mathrm{L}$ after $30 \mathrm{~min}$. Similarly, Soni and Shukla (2019) reached a maximum arsenate adsorption capacity of $49.23 \mu \mathrm{g} / \mathrm{g}$ for $100 \mu \mathrm{g} / \mathrm{L}$ of initial arsenic concentration at $\mathrm{pH} 7$ with the rGO-fly ash-based zeolite composite. In this study, composite material consisting of GO synthesized using Hummer method and clinoptilolite modified by iron was used as an adsorbent in arsenate adsorption from aqueous solution in order to combine the superior properties of both materials.

Most of the studies on removing arsenic from water by adsorption method were carried out only according to the batch adsorption experiments, and it is very difficult to apply results of these studies directly to the fixedbed column reactors (Singh and Pant 2006; Dhoble et al. 2017). Column operations are essential to find data which can be realized for industrial and household objectives (Roy et al. 2013). There are few studies on arsenate removal from waters by the column process (Pang et al. 2020; Yin et al. 2017; Guo et al. 2007). However, there is no study in the literature in which column experiments were carried out for arsenate adsorption using GO-based composite materials. In our previous study, the arsenate adsorption efficiencies of the GO-iron 
modified clinoptilolite composites obtained by combining the two materials in different ratios were determined by batch adsorption experiments. The maximum arsenate uptake was realized in the $\mathrm{pH}$ range of 6 to 8 and optimum dose were determined as the $0.8 \mathrm{~g} / \mathrm{L}$ for the composite materials (Bilici Baskan and Hadimlioglu 2021). In the present study, as the continuation of our previous study, arsenate uptake on GO-iron modified clinoptilolite composites was examined by both kinetic and column studies. The present paper also informs the synthesis and characterization of GO-iron modified clinoptilolite composites. Furthermore, the adsorption kinetics of arsenate were determined to understand the adsorption mechanism. The characterization of composites after arsenate adsorption was also investigated to verify the arsenate adsorption and to reveal the adsorption mechanism. The most important aim of this study is to run column experiments in order to determine the breakthrough point and thus to reveal the operation period and regeneration time for potential large-scale application.

\section{Experimental}

\section{Materials and reagents}

Graphite powder, sulphuric acid $\left(\mathrm{H}_{2} \mathrm{SO}_{4}\right)$, hydrochloric acid $(\mathrm{HCl})$, sodium nitrate $\left(\mathrm{NaNO}_{3}\right)$, sodium hydroxide $(\mathrm{NaOH})$, potassium permanganate $\left(\mathrm{KMnO}_{4}\right)$, sodium chloride $(\mathrm{NaCl})$, ferric chloride $\left(\mathrm{FeCl}_{3}\right)$, and hydrogen peroxide $\left(\mathrm{H}_{2} \mathrm{O}_{2}\right)$ were all analytical grade and used without any further purification. Sodium arsenate $\left(\mathrm{Na}_{2} \mathrm{HA}\right.$ $\mathrm{sO}_{4} \cdot 7 \mathrm{H}_{2} \mathrm{O}$ ) was chosen as the arsenate source, and the stock solution of $1 \mathrm{mg} / \mathrm{L}$ was used to prepare arsenate solution at different concentrations. Furthermore, clinoptilolite with $0.5-1.0-\mathrm{mm}$ particle size extracted from Gördes-Manisa was used.

\section{Preparation of samples Synthesis of GO}

In GO synthesis performed using the modified Hummer method (Hummers and Offeman 1958), primarily graphite powder $(10 \mathrm{~g})$ and $\mathrm{NaNO}_{3}(10 \mathrm{~g})$ were put in the concentrated $300 \mathrm{~mL}$ of $\mathrm{H}_{2} \mathrm{SO}_{4}$ at $0{ }^{\circ} \mathrm{C}$ in an ice bath. $\mathrm{KMnO}_{4}(30 \mathrm{~g})$ was gradually added while the suspension was continued to stir permanently and the temperature was kept constant at $35{ }^{\circ} \mathrm{C}$ by means of an ice bath. After $3 \mathrm{~h}$, it was diluted by adding distilled water (900 $\mathrm{mL}$ ) under continuous stirring. Then, $35 \% \mathrm{H}_{2} \mathrm{O}_{2}$ solution $(48 \mathrm{~mL})$ was slowly added into the mixture and it was observed that the color of the mixture turned light brown and yellow. The solid phase obtained by centrifuging and filtering of the mixture was washed multiple times with distilled water to remove acid. Finally, it was dried at $60{ }^{\circ} \mathrm{C}$ and $\mathrm{GO}$ samples were obtained.

\section{Preparation of iron modified clinoptilolite}

For this purpose, $10 \mathrm{~g}$ of clinoptilolite was treated with $0.1 \mathrm{M} \mathrm{NaCl}$ solution under reflux to change its surface properties. After separating the solid-liquid phase by centrifugation, the process under reflux was repeated using the newly prepared $\mathrm{NaCl}$ solution. The solid phase obtained was dried at $60{ }^{\circ} \mathrm{C}$ for $24 \mathrm{~h} .10 \mathrm{~g}$ of this sample were treated with $0.1 \mathrm{M} \mathrm{FeCl}_{3}$ solution for $5 \mathrm{~h}$ and this process was repeated 2 times. The solid-liquid phase separation was carried out by centrifuging at $3000 \mathrm{rpm}$ for $20 \mathrm{~min}$, and then the solid phase was washed with distilled water and dried for $24 \mathrm{~h}$ at $60{ }^{\circ} \mathrm{C}$. This sample was named $\mathrm{FeZ}$ and stored in a dry atmosphere until used.

\section{Preparation of FeZ-GO composites}

The sample formed by taking $2 \mathrm{~g}$ of $\mathrm{GO}$ and $2 \mathrm{~g}$ of FeZ was named as GOFeZA and the sample obtained by taking $2 \mathrm{~g}$ of GO and $4 \mathrm{~g}$ of FeZ was called as GOFeZB. The samples were sonicated for $3 \mathrm{~h}$ in $60 \mathrm{~mL}$ of ethanol. The mixtures were then consistently mixed until the solvents had evaporated. FeZ-GO composite materials (GOFeZA and GOFeZB) were obtained by drying the formed precipitates at $60{ }^{\circ} \mathrm{C}$.

\section{Characterization and measurements}

Scanning electron microscopy (SEM) photographs and energy dispersive $\mathrm{x}$-ray spectroscopy analysis (EDS) of GO, FeZ, GOFeZA, and GOFeZB were achieved by Zeiss brand Supra $40 \mathrm{VP}$ model scanning electron microscope running at $5 \mathrm{kV}$. X-ray fluorescence spectrometry (XRF) was used to determine the elemental compositions of adsorbents. Spectro XEPOS-II PEDXRF device used for this purpose was operated at $35-\mathrm{kV}$ voltage and $1-\mathrm{mA}$ current. The Fourier transform infrared (FTIR) spectra of the samples were carried out using Thermo Scientific Nicolet iS50 FTIR spectrophotometer. The $\mathrm{pH}$ values of the points of zero charge $\left(\mathrm{pH}_{\mathrm{pzc}}\right)$ of GO, FeZ, GOFeZA, and GOFeZB were measured using $0.1 \mathrm{M} \mathrm{KNO}_{3}$ solution. The initial $\mathrm{pH}$ values of the solutions were adjusted in the range of 2-12 using $0.1 \mathrm{M} \mathrm{HCl}$ or $\mathrm{NaOH}$ solutions. After the initial $\mathrm{pH}$ value of the solution was determined, the samples were added to the each solution and then shaken for $48 \mathrm{~h}$. After all the samples were centrifuged and filtered, the $\mathrm{pH}$ values of the obtained solution were measured and recorded as the final $\mathrm{pH}$ value of the solution. The concentrations of arsenate were analyzed by the inductively coupled plasma-mass spectrometer (ICP-MS). The average of three readings for each sample was given as a result of arsenate analysis.

\section{Assessment of arsenate adsorption}

$0.04 \mathrm{~g}$ of each composite material (GOFeZA and GOFeZB) was put into $50 \mathrm{~mL}$ of arsenate solution with 
different initial arsenate concentration. The $\mathrm{pH}$ values of the solutions were adjusted to the desired values using the discardable volume of $0.1 \mathrm{M}$ and $0.01 \mathrm{M} \mathrm{HCl}$ or $\mathrm{NaOH}$ solutions. The mixtures were shaken at $150 \mathrm{rpm}$ and room temperature $\left(20 \pm 1{ }^{\circ} \mathrm{C}\right)$ for $24 \mathrm{~h}$ and samples were taken from the shaker at various time periods during $24 \mathrm{~h}$. The collected samples were first centrifuged at $3000 \mathrm{rpm}$ for $20 \mathrm{~min}$, and then filtered using a syringe filter with a $0.45-\mu \mathrm{m}$ pore size in order to separate the adsorbents. The following Eq. 1 was used to determine the amount of arsenate adsorbed:

$$
q_{e}=\frac{V\left(C_{0}-C_{e}\right)}{m}
$$

where $q_{e}$ is the arsenate adsorption capacity of composite materials at equilibrium $(\mu \mathrm{g} / \mathrm{g}) ; V$ is volume of arsenate solution (L); $C_{O}$ and $C_{e}$ are the initial and equilibrium arsenate concentrations, respectively $(\mu \mathrm{g} / \mathrm{L})$; and $m$ is the amount of composites (g) used in the batch adsorption experiments.

\section{Adsorption kinetics}

The adsorption kinetic studies were carried out by using GOFeZA and GOFeZB composites at three different initial arsenate concentrations as a function of time. Pseudo first order and pseudo second order kinetic models were used in the kinetic studies to determine the rate of arsenate adsorption on composite materials.

\section{Fixed-bed column experiments}

The fixed-bed column experiments were performed using GOFeZA composite (as the best composite of our work) to examine the potential large-scale application. A clean and dry fixed-bed column reactor with diameter of $2 \mathrm{~cm}$ and length of $33.5 \mathrm{~cm}$ and made of glass was used for this purpose. As shown in Fig. 1, the lower part of the column was covered using glass wool and the top of the glass wool was filled with $33.42 \mathrm{~g}$ of GOFeZA composite with a height of $15 \mathrm{~cm}$. The bed volume of the system was $47.1 \mathrm{~mL}$. After the GOFeZA composite in the column was saturated by passing distilled water, the solution containing $100 \mu \mathrm{g} / \mathrm{L}$ of arsenate was passed through the column at a flow rate of $1.7 \mathrm{~mL} / \mathrm{min}$. The arsenate solution was pumped through the column from top to bottom using the peristaltic pump and the passage of the arsenate solution through the column continued until the GOFeZA composite was saturated. Arsenate analysis was performed using samples taken from the column effluent at certain time intervals. In this study, the performance of GOFeZA composite in continuous adsorption experiments was evaluated using the breakthrough point and arsenate adsorption effectiveness after regeneration of the saturated composite.

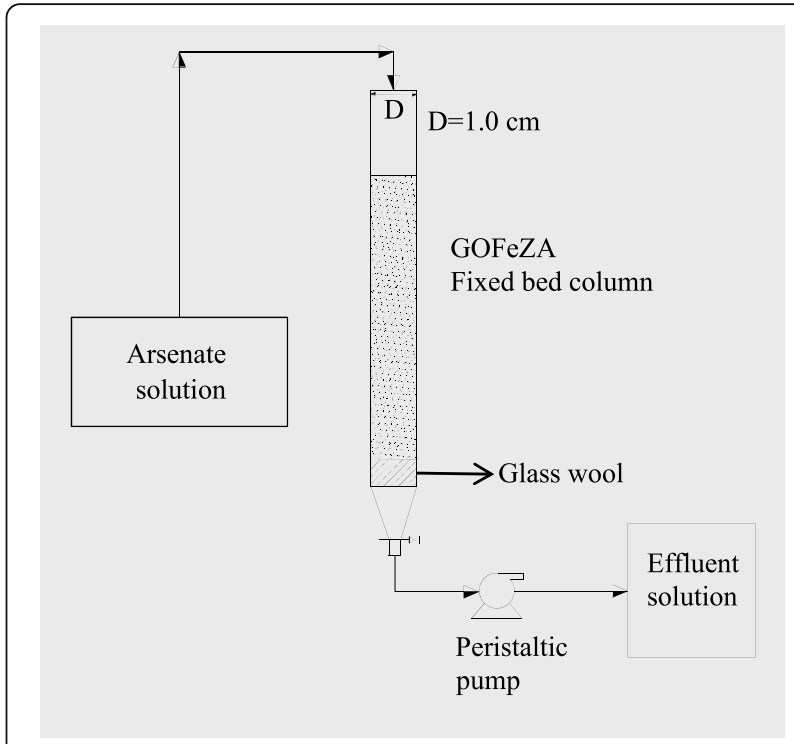

Fig. 1 Schematic diagram of the fixed-bed column experiment

\section{Results and discussion Characterization}

The morphologies of FeZ, GO, GOFeZA, and GOFeZB were investigated by SEM images and the relevant images are given in Fig. 2a-d. The SEM morphology in Fig. 2a shows very clearly dispersed crystals, extensive clusters, and illimitable number of pores on the surface of FeZ. The elemental compositions of GO, FeZ, GOFeZA, and GOFeZB are also given in Table 1. FeZ mainly contains elements of $\mathrm{Al}, \mathrm{Si}$, and $\mathrm{Fe}$ and also contains fewer percentages of $\mathrm{K}, \mathrm{Ca}, \mathrm{Na}$, and $\mathrm{Mg}$ by weight. The presence of more $\mathrm{Al}$ and $\mathrm{Si}$ in $\mathrm{FeZ}$ indicates that clinoptilolite is basically aluminosilicate. In addition, considering the weight percentage of $\mathrm{Na}, \mathrm{Mg}, \mathrm{K}$, and $\mathrm{Ca}$, it can be concluded that the clinoptilolite used in the study is the K-Ca type. Its Fe content of about $28 \%$ by weight indicates that the iron was incorporated efficiently into the clinoptilolite. Additionally, the EDS spectra of the samples were used to verify their elemental composition and illustrated in Fig. 2e-h. The EDS spectra of FeZ (Fig. 2e) also show the presence of basic elements such as $\mathrm{Al}$ and $\mathrm{Si}$ in the clinoptilolite. Moreover, the Fe peak between 6.0 and $7.0 \mathrm{keV}$ reveals the presence of iron binding to clinoptilolite. The GO image given in Fig. 2b demonstrates that GO is in the form of flaky and smooth texture representing its layered structure. Moreover, the fact that the elemental composition of GO demonstrates the presence of oxygen and carbon indicates the formation of GO. The EDS spectra of GO shown in Fig. $2 f$ also indicates the presence of carbon and oxygen, as well as the presence of sulfur, which is lacking in the elemental composition of GO in Table 1 and resulting from the production of GO by the Hummer method. The EDS 

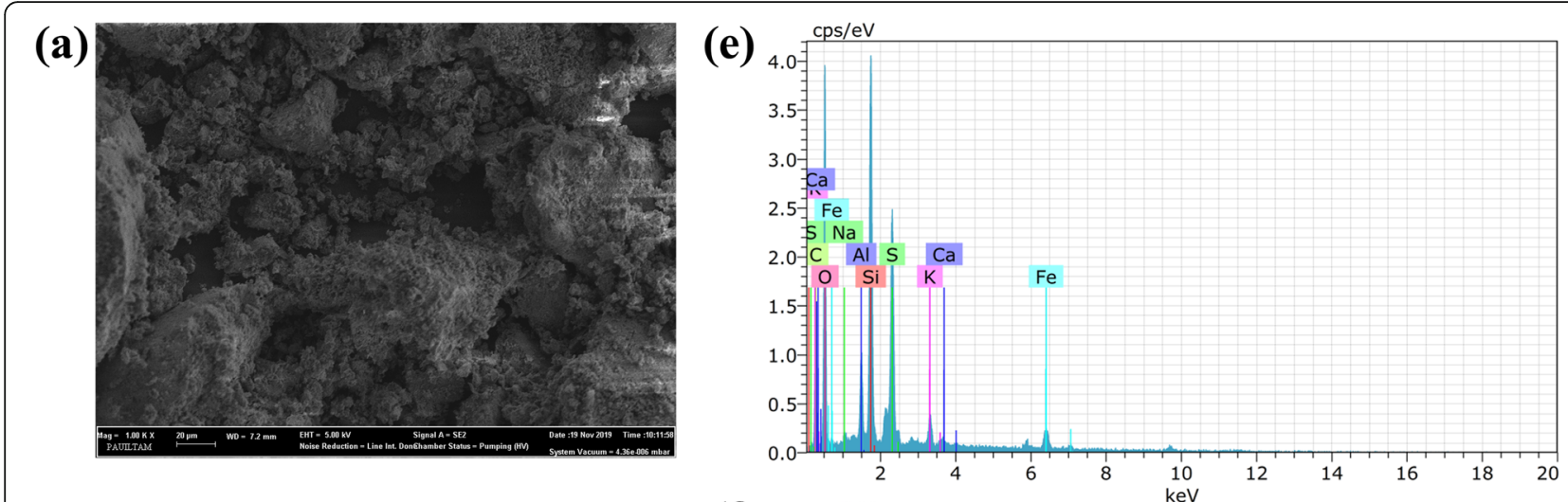

(b)

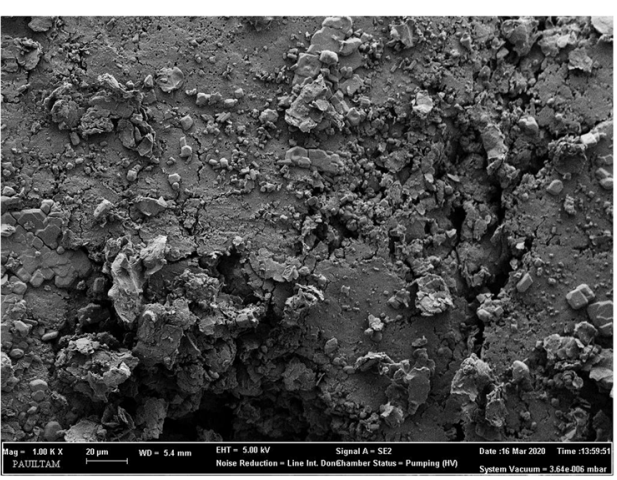

(f)

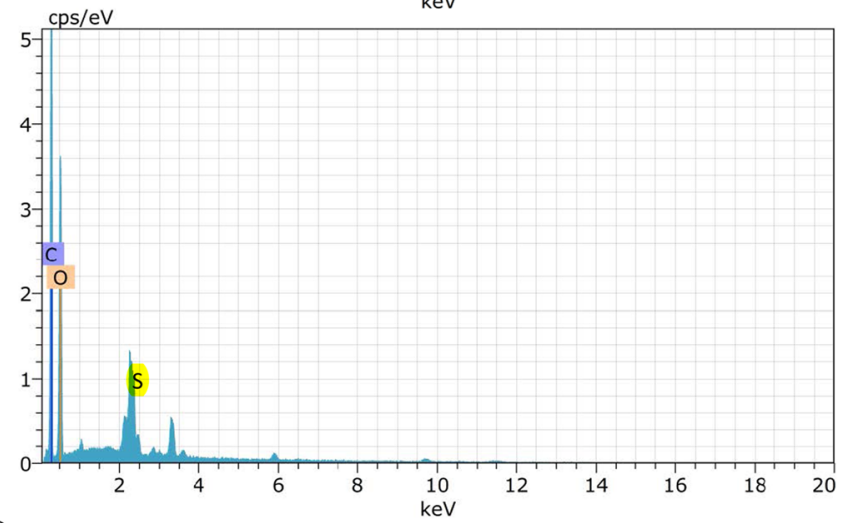

(c)

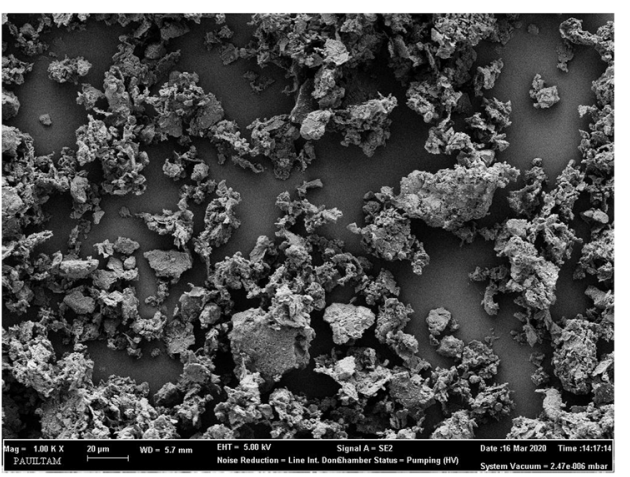

(g)

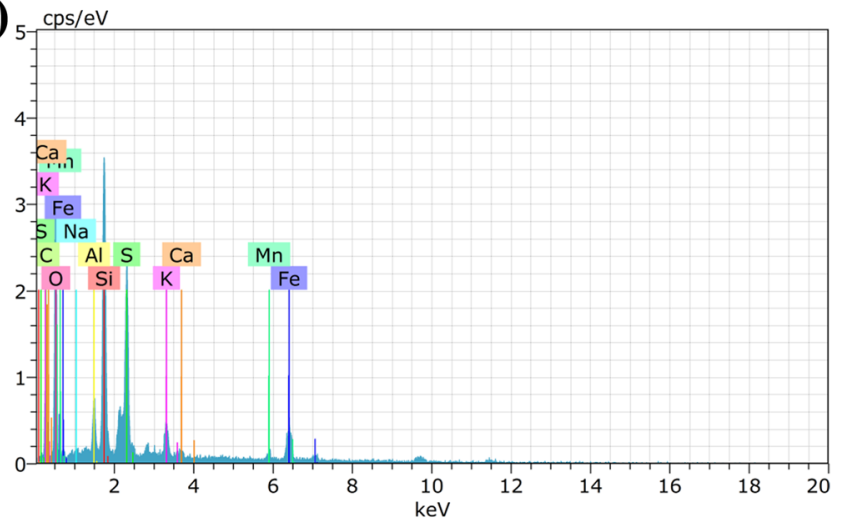

(d)

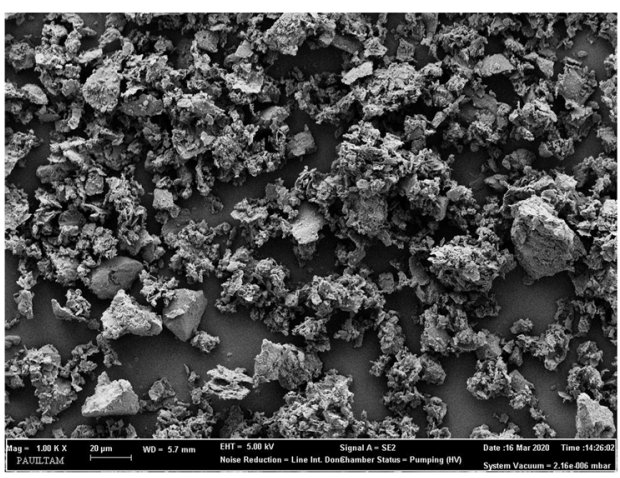

(h)

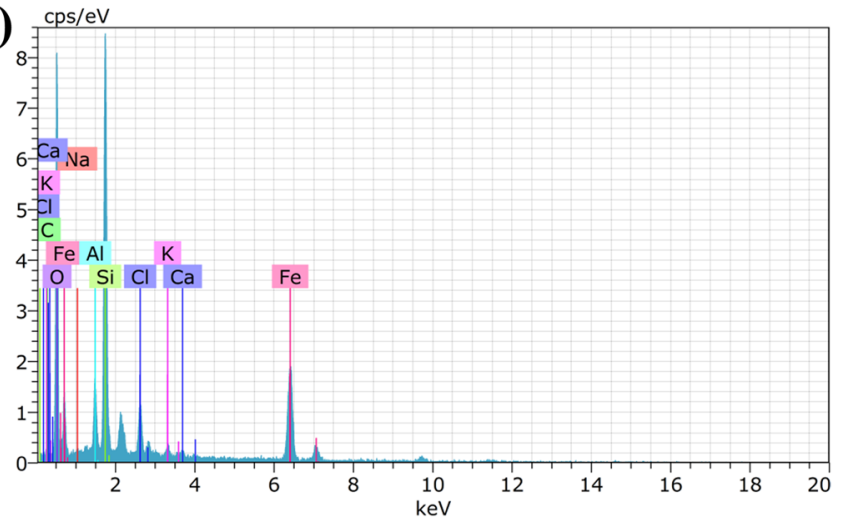

Fig. 2 SEM images of a FeZ, b GO, c GOFeZA, and $\mathbf{d}$ GOFeZB with magnification of 1000 and EDS spectrum of e FeZ, $\mathbf{f} G O, \mathbf{g} G O F e Z A$, and h GOFeZB 
Table 1 Elemental compositions of GO, FeZ, GOFeZA, and GOFeZB

\begin{tabular}{|c|c|c|c|c|c|c|c|c|c|}
\hline \multirow[t]{2}{*}{ Element } & \multicolumn{9}{|c|}{ Composition (weight, \%) } \\
\hline & 0 & $\mathrm{C}$ & $\mathrm{Na}$ & $\mathrm{Mg}$ & Al & $\mathrm{Si}$ & $\mathrm{K}$ & $\mathrm{Ca}$ & $\mathrm{Fe}$ \\
\hline GO & 39.720 & 53.264 & - & - & - & - & - & - & - \\
\hline $\mathrm{FeZ}$ & 28.460 & - & 0.027 & 0.220 & 5.426 & 25.890 & 1.463 & 0.846 & 28.460 \\
\hline GOFeZA & 41.561 & 41.280 & 0.011 & 0.100 & 1.230 & 5.462 & 0.881 & 0.232 & 8.438 \\
\hline GOFeZB & 40.025 & 38.573 & 0.015 & 0.185 & 1.574 & 6.501 & 1.012 & 0.365 & 10.670 \\
\hline
\end{tabular}

spectrum of GO also shows the oxygen functional groups bearing by the synthesized GO sheets (Singh et al. 2018). The SEM images of GOFeZA and GOFeZB composites (Fig. 2c, d) exposed that the GO flexible sheets were decorated with FeZ particles. This approves that FeZ particles were spread overall the GO. The spherical particle structure of GOFeZA and GOFeZB composites may have been caused by the self-assembly between FeZ and GO due to hydrogen bonding and Van der Waals forces (Soni and Shukla 2019). On the other hand, different from the elements in the FeZ, the carbon and oxygen percentages observed in GOFeZA and GOFeZB composites successfully support the composites formation. The XRF data explicitly approve the presence of iron on the composites. The fact that the EDS diagrams of GOFeZA and GOFeZB (Fig. 2g, h) contain elements such as $\mathrm{Al}, \mathrm{Si}$, and $\mathrm{Fe}$ found in $\mathrm{FeZ}$ as well as carbon and oxygen, which indicate the presence of GO, proves the successful formation of composites. In addition, the EDS spectra and XRF data of the composites prove that more $\mathrm{FeZ}$ was used in the process of the obtaining composite of GOFeZB.

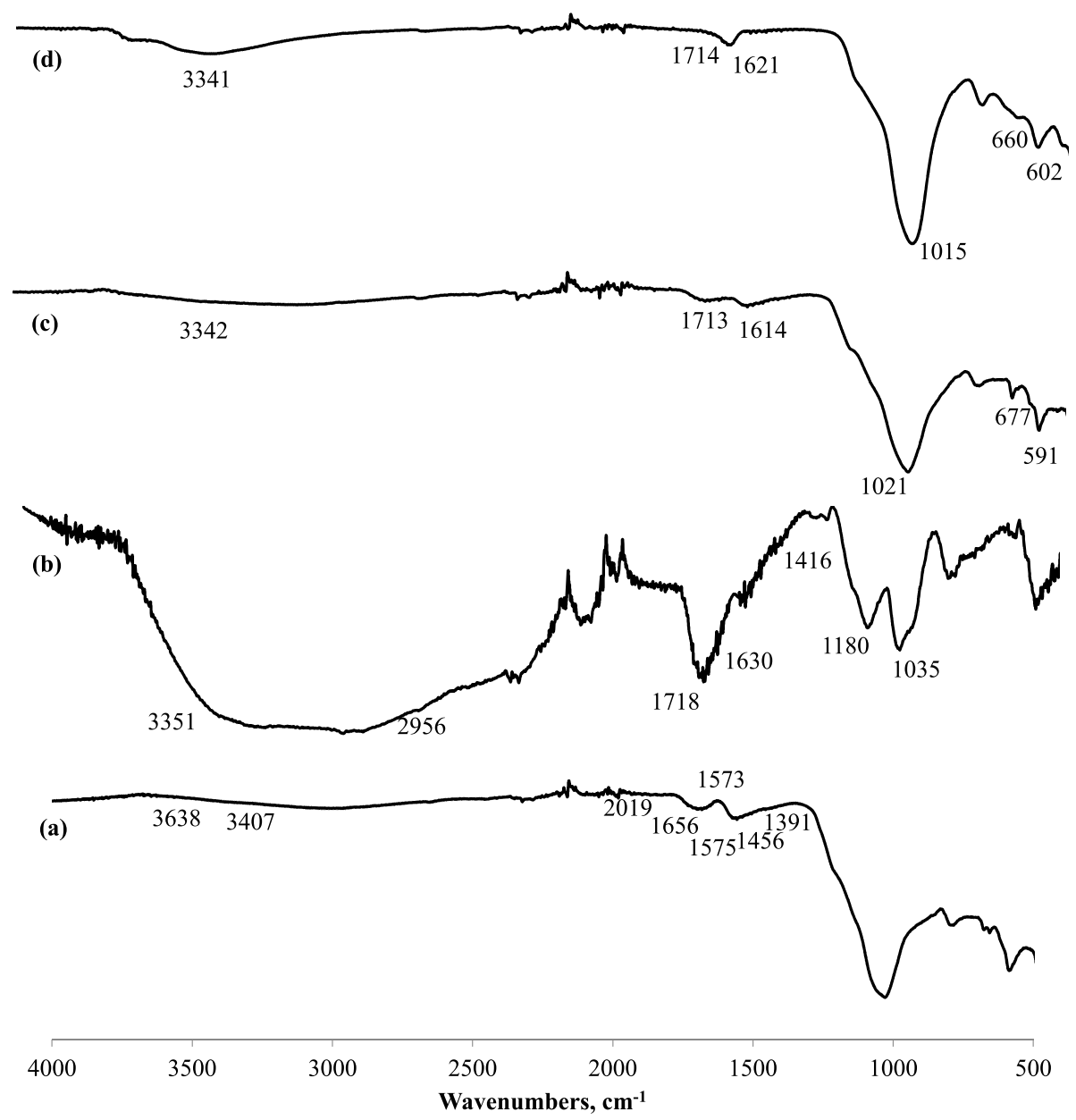

Fig. 3 FTIR absorption spectra of a FeZ, b GO, c GOFeZA, and d GOFeZB 
The surface functional groups of GO, FeZ, GOFeZA, and GOFeZB were determined using FTIR analysis and the FTIR spectra of them are illustrated in Fig. 3a-d. The FTIR spectrum of FeZ is represented in Fig. 3a. The small peak observed around $3638 \mathrm{~cm}^{-1}$ can be assigned to the dissociation of $\mathrm{O}-\mathrm{H}$ and the symmetric and asymmetric $\mathrm{OH}$ stretching vibration (Ruiz-Baltazar et al. 2015; Tasharrofi et al. 2020). The peaks around 3407 and $1656 \mathrm{~cm}^{-1}$ are related to the $\mathrm{H}-\mathrm{O}-\mathrm{H}$ stretching vibration and $\mathrm{O}-\mathrm{H}$ bending vibration of clinoptilolite water molecules. In addition, the peaks at approximately 1575 and $2019 \mathrm{~cm}^{-1}$ represent the vibration of the S-O and Al-O bands, respectively (Ruiz-Baltazar et al. 2015). The bands situated at 1391, 1456, and $1573 \mathrm{~cm}^{-1}$ indicate the presence of the surface iron hydroxide groups on the clinoptilolite (Guaya et al. 2016; Abaei et al. 2017). The fairly broad absorption peak of GO observed between 3351 and $2956 \mathrm{~cm}^{-1}$ (Fig. 3b) can be attributed to the $\mathrm{O}-\mathrm{H}$ stretching vibration of the adsorbed water molecules (Sherlala et al. 2019; Luo et al. 2013). Additionally, the absorption peaks observed at 1718, 1630, 1416,1180 , and $1035 \mathrm{~cm}^{-1}$ in the FTIR spectrum of GO show the $\mathrm{C}=\mathrm{O}$, aromatic $\mathrm{C}=\mathrm{C}, \mathrm{C}-\mathrm{O}$ group related to carboxyl, $\mathrm{C}-\mathrm{O}$ group related to epoxy, and $\mathrm{C}-\mathrm{O}$ group related to alkoxy, respectively (Su et al. 2017). The mentioned different peaks showed the availability of different functional groups on the surface of GO. The peaks observed at 591, 677, and $1021 \mathrm{~cm}^{-1}$ in the FTIR spectra of GOFeZA given in Fig. $3 \mathrm{c}$ and the peaks observed at 602 , 660 , and $1015 \mathrm{~cm}^{-1}$ in the FTIR spectra of GOFeZB given in Fig. $3 \mathrm{~d}$ are characteristic peaks related to the stretching vibration of the $\mathrm{T}-\mathrm{O}$ bands resulting from the $\mathrm{TO}_{4}$ ( $\mathrm{T}$ is $\mathrm{Al}$ or $\mathrm{Si}$ ) structure of the clinoptilolite (Huang et al. 2019; Khatamian et al. 2017). Furthermore, the peaks of $\mathrm{GO}$ showing groups such as $\mathrm{O}-\mathrm{H}, \mathrm{C}=\mathrm{O}$, and aromatic $\mathrm{C}=\mathrm{C}$ are also detected in the FTIR spectrum of composites at around 3341, 1718, and $1620 \mathrm{~cm}^{-1}$, respectively. These results show that composites were synthesized accomplishedly using GO and FeZ.

\section{Effect of $\mathrm{pH}$}

In the process of arsenate adsorption from aqueous solution, the $\mathrm{pH}$ value of the solution is a very substantial parameter since it affects both the arsenate speciation and the surface charge of the adsorbent. The $\mathrm{pH}$ value of the solution is effective in protonating or deprotonating of the adsorbent surface (Sherlala et al. 2019). Although the arsenate species are negatively charged in all cases where the $\mathrm{pH}$ value is above 2.2 , the monovalent form of arsenate is dominant if the $\mathrm{pH}$ is less than 6.9 and the divalent form of arsenate is dominant if the $\mathrm{pH}$ is greater than 6.9 (Lingamdinne et al. 2019; Yoon et al. 2017). In extreme acidic and alkaline conditions, uncharged and trivalent forms of arsenate are dominant, respectively. The effect of $\mathrm{pH}$ on arsenate adsorption performed using GO, FeZ, GOFeZA, and GOFeZB was examined for the initial $\mathrm{pH}$ value between 3 and 11 and the obtained results were shown in the Fig. 4. Arsenate adsorption capacity of $\mathrm{GO}$ decreased as the $\mathrm{pH}$ value was increased. At the low $\mathrm{pH}$ values, the $\mathrm{GO}$ surface is positively charged. When the $\mathrm{pH}$ is above 2.2 , since the anionic species of the arsenate are in the solution, it was attracted to the positively charged GO surface by the effect of electrostatic forces and was removed from the aqueous solution more easily. Since the $\mathrm{pH}_{\mathrm{pzc}}$ values of GO, FeZ, GOFeZA, and GOFeZB are an important factor in the interaction of arsenate ions in aqueous solution with their own surfaces, the $\mathrm{pH}_{\mathrm{pzc}}$ value is considered to be a significant factor controlling the adsorption process. If the $\mathrm{pH}$ value is lower than $\mathrm{pH}_{\mathrm{pzc}}$, the surface of the adsorbent is positively charged, while at $\mathrm{pH}$ values higher than $\mathrm{pH}_{\mathrm{pzc}}$, the adsorbent surface is negatively charged (Yoon et al. 2017). In this study, $\mathrm{pH}_{\mathrm{pzc}}$ values of $\mathrm{GO}$ were determined as 3.98. The $\mathrm{pH}_{\mathrm{pzc}}$ values found in other studies for GO generally vary between 3.1 and 4.0 (Bian et al. 2015; Rodriguez et al. 2020). The value found in this study is also within this range and this value explains the higher adsorption capacity obtained at $\mathrm{pH}$ values below 4 . On the other hand, the arsenate adsorption capacity of FeZ increased up to $\mathrm{pH}$ value 9 and decreased at $\mathrm{pH}$ values above 9. The adsorption of arsenate on FeZ could be clarified by the $\mathrm{pH}_{\mathrm{pzc}}$ value of the adsorbent determined as 9.11. The determined $\mathrm{pH}_{\mathrm{pzc}}$ value explains the increase in arsenate adsorption capacity of $\mathrm{FeZ}$ with $\mathrm{pH}$ increase up to 9 . The negatively charged surface sites on the FeZ at the $\mathrm{pH}$ above 9.11 prevented the negatively charged arsenate adsorption in the water.

The $\mathrm{pH}_{\mathrm{pzc}}$ values of GOFeZA and GOFeZB were determined as 7.13 and 7.88 , respectively. The arsenate adsorption capacities of GOFeZA and GOFeZB were increased with raising solution $\mathrm{pH}$ from 3 to 7 and were maximum in the $\mathrm{pH}$ range of $7-8$. At the $\mathrm{pH}$ values

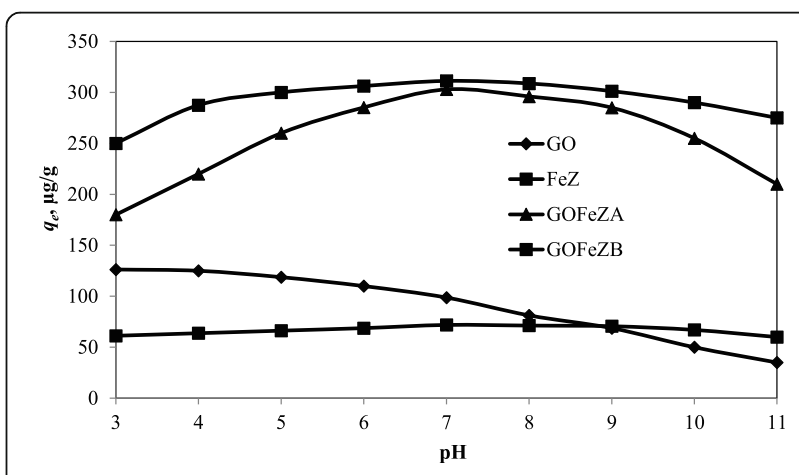

Fig. 4 The effect of $\mathrm{pH}$ on arsenate adsorption by GO, FeZ, GOFeZA, and GOFeZB 
above 8 , their adsorption capacities were decreased. The low adsorption capacities in acidic $\mathrm{pH}$ conditions where $\mathrm{pH}$ is less than $\mathrm{pH}_{\mathrm{pzc}}$ could be explained by the small interaction between the uncharged and monovalent form of arsenate species and the positive surfaces of composites. Electrostatic interaction is unlikely due to the repulsive force between the negative surfaces of the composites and the monovalent and divalent form of arsenate species at $\mathrm{pH}$ values above 7 for GOFeZA and 8 for GOFeZB. Significant adsorption capacities that occurred even when $\mathrm{pH}_{\text {pzc }}$ values are higher than the solution $\mathrm{pH}$ show that not only electrostatic interaction but also ion exchange and surface complexation are effective in arsenate adsorption on composites. Similar results were obtained in previous studies on arsenic adsorption with GO-based composite materials (Lingamdinne et al. 2019; Wang et al. 2014).

\section{Adsorption kinetics}

Firstly, batch adsorption experiments were carried out for $9 \mathrm{~h}$ at three different initial arsenate concentrations to demonstrate the effectiveness of FeZ, GO, GOFeZA, and GOFeZB in arsenate adsorption from aqueous solutions. As can be observed from Fig. $5 \mathrm{a}-\mathrm{c}$, the increase in the initial arsenate concentration from 50 to $450 \mu \mathrm{g} / \mathrm{L}$ caused the arsenate concentrations remaining in the water to increase for all types of adsorbent. The decrease in the initial concentration of arsenate in the solution causes the interaction of most of the arsenate ions in the water with the binding sites on the adsorbent, causing an increase in the adsorption performance (Soni and Shukla 2019). At the initial arsenate concentration of $250 \mu \mathrm{g} / \mathrm{L}$ and at the end of the $3 \mathrm{~h}$ of contact time, the remaining arsenate concentrations in the solution were analyzed as $192.50,169.35,1.92$, and $5.10 \mu \mathrm{g} / \mathrm{L}$ for $\mathrm{FeZ}$, GO, GOFeZA, and GOFeZB, respectively. These values indicate that composites have much higher and significant arsenate removal efficiencies in arsenate adsorption than FeZ and GO. In addition, at the three different initial arsenate concentrations, both composites succeeded in reducing the residual arsenate concentration in the water below $10 \mathrm{ppb}$, which is the maximum contaminant level (MCL) determined by the WHO at the end of the contact time of about $2 \mathrm{~h}$. Therefore, kinetic studies were performed using only GOFeZA and GOFeZB composites.

Two significant kinetic models were used to research the adsorption operation and to understand the properties of arsenate adsorption on GOFeZA and GOFeZB composites by utilizing the results of experimental kinetic studies. In order to establish the arsenate kinetics, arsenate adsorption on composites was investigated as a function of initial arsenate concentration and contact time, and the obtained results are given in Fig. $6 \mathrm{a}, \mathrm{b}$.
Arsenate adsorption kinetics on GOFeZA and GOFeZB were examined at three different initial arsenate concentrations as 50,250 , and $450 \mu \mathrm{g} / \mathrm{L}$ and at $7 \mathrm{of} \mathrm{pH}$. The kinetic profiles demonstrated that the adsorption process takes place very rapidly in the first $3 \mathrm{~h}$, and then the removal rate gradually decreases until the system reaches equilibrium. Since a significant part of the active binding areas on the adsorbent surface is covered by arsenate ions, the system has reached saturation after $3 \mathrm{~h}$. The relatively low equilibrium time and fast arsenate removal are due to considerably sufficient adsorptive interactions. The higher arsenate uptake in the early stages of the process is due to the fact that there are still large number and suitable areas for sorption at this stage. This result indicated that the adsorption process probably consists of 2 stages, nominately, surface complexation or ion exchange, and electrostatic attraction between GOFeZA or GOFeZB and arsenate ions in the aqueous solution (Guo et al. 2015; Khatamian et al. 2017; Luo et al. 2012). Arsenate adsorption mechanism on GObased composites is quite complicated. Arsenate adsorption of graphene-based composites in literature is mostly explained by the electrostatic attraction, intraparticle diffusion, and physical adsorption mechanisms (Soni and Shukla 2019; Yoon et al. 2017; Guo et al. 2015).

It is further found out from the results that the time for the system to reach equilibrium is independent of the initial arsenate concentration. But Fig. 6a, b illustrates that the adsorption capacity increases with the increase of the initial arsenate concentration for both composites at equilibrium. This result states that the initial concentration is important in the arsenate adsorption on the composites. At the end of the $3 \mathrm{~h}$ of equilibrium time and at the initial arsenate concentration of $50 \mu \mathrm{g} / \mathrm{L}$, the arsenate adsorption on GOFeZA and GOFeZB was 63.46 and $59.85 \mu \mathrm{g} / \mathrm{g}$, respectively, while the adsorption capacities of GOFeZA and GOFeZB at the initial arsenate concentration of $450 \mu \mathrm{g} /$ $\mathrm{L}$ were calculated as 557.86 and $554.64 \mu \mathrm{g} / \mathrm{g}$, respectively. This represents that as the initial arsenate concentration increases, much more arsenate ions to be adsorbed on the surface of the composites are present in the solution and this leads to an increase in the adsorption performance of them (Bilici Baskan and Pala 2011).

It is of great importance to estimate the performance of the used adsorbent and to understand the mechanism that occurs. Adsorption kinetic is a substantial property used in describing the adsorption efficiency. There are models with different complexity degrees to determine the adsorption kinetics in batch adsorption studies (Okoli and Ezuma 2014). It is very important to know the kinetics of the removal of the pollutant from the solution in determining the optimum operating parameters of full scale systems (Adane et al. 

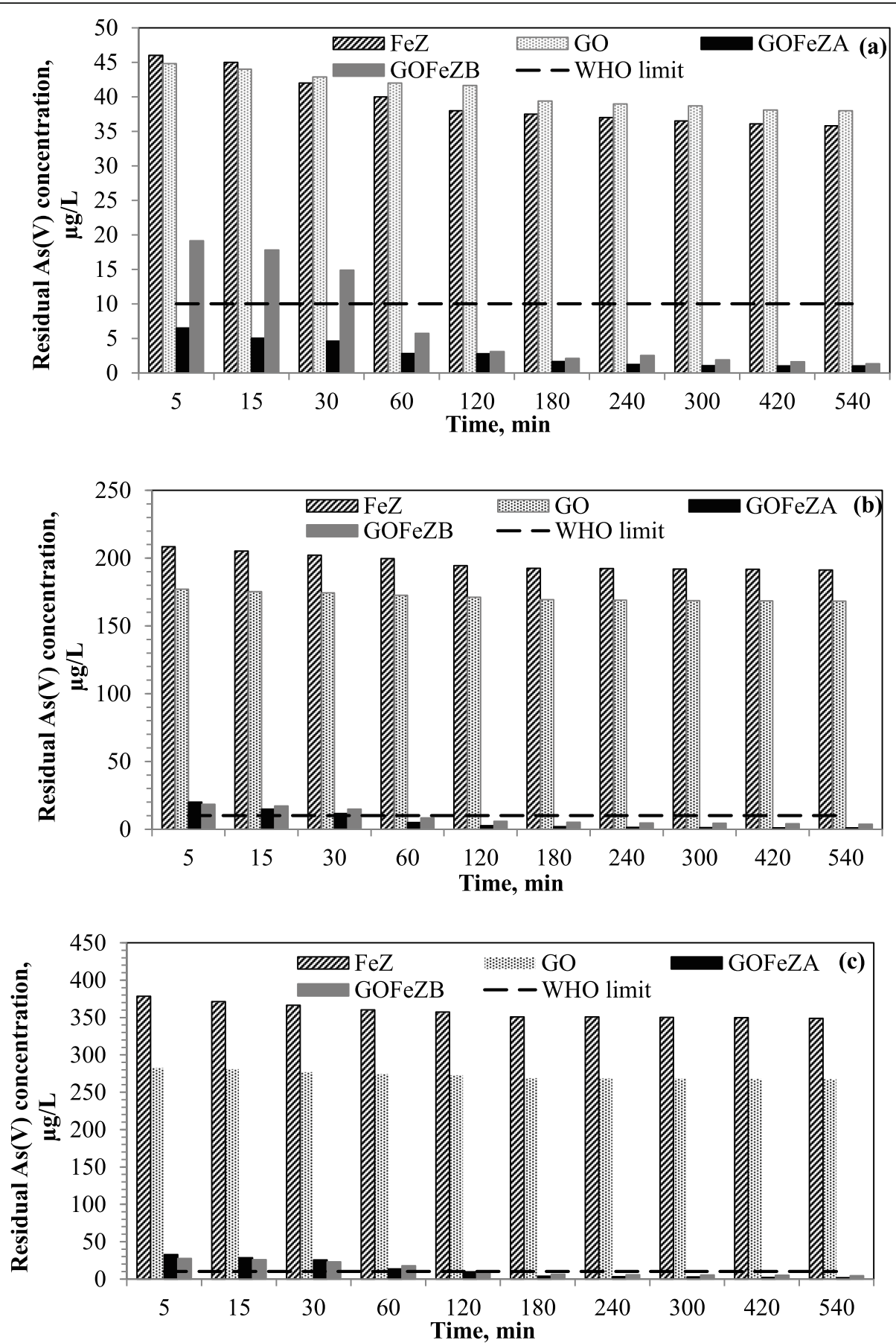

Fig. 5 Effects of initial arsenate concentration of a $50 \mu \mathrm{g} / \mathrm{L}, \mathbf{b} 250 \mu \mathrm{g} / \mathrm{L}$, and c $450 \mu \mathrm{g} / \mathrm{L}$ on the residual arsenate concentration for FeZ, GO, GOFeZA, and GOFeZB

2020). In this study, the results of the relevant experimental kinetic studies were evaluated using pseudo first order and pseudo second order kinetic models in order to understand the arsenate adsorption mechanism. The following equation developed by Lagergren is used for the pseudo first order kinetic model (Ho 2004):

$$
\log \left(q_{e}-q_{t}\right)=\log q_{e}-\frac{K_{1}}{2.303} t
$$



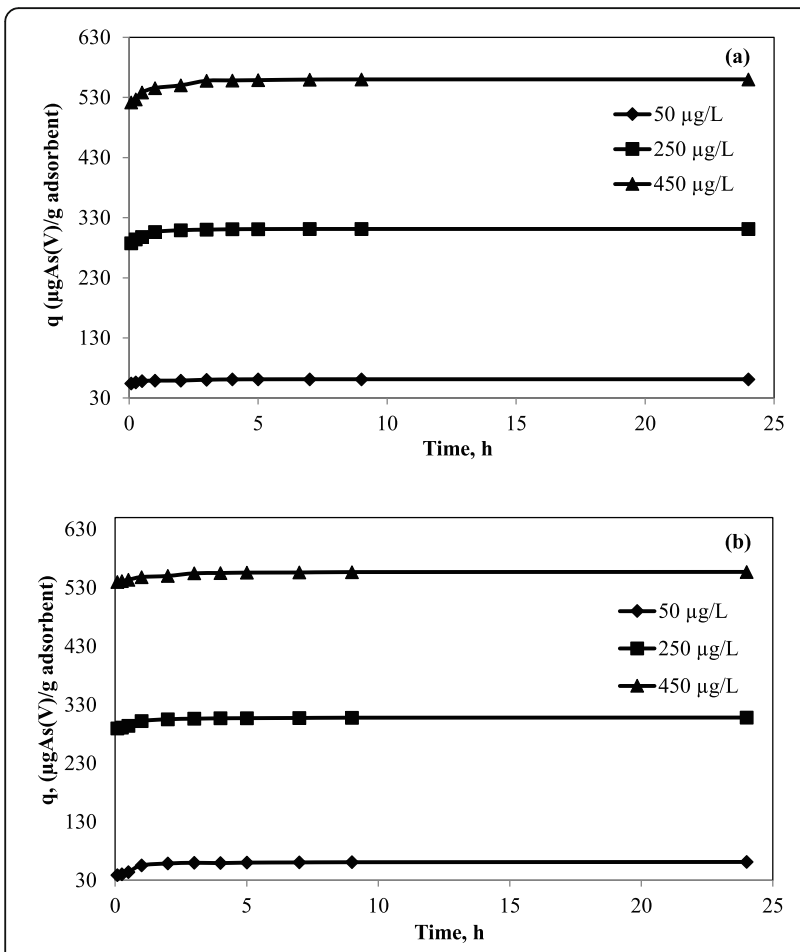

Fig. 6 Arsenate adsorption onto a GOFeZA and $\mathbf{b}$ GOFeZB as a function of time for varying initial arsenate concentration

where $q_{t}(\mu \mathrm{g} / \mathrm{g})$ is the amount of arsenate adsorbed on the composites at time $t, t(\mathrm{~min})$ is the time and $K_{1}(1 /$ $\mathrm{min})$ is the rate constant of pseudo first order kinetic model. For the investigated initial concentrations, $K_{1}$ and theoretical equilibrium arsenate adsorption capacities of composites were calculated using the slope and intercept of the linear plots of the $\log \left(q_{e}-q_{t}\right)$ against $t$, respectively, and the graphs for GOFeZA and GOFeZB are shown in Fig. $7 \mathrm{a}$, b. In addition, calculated $K_{1}$ and the amount of arsenate adsorbed at equilibrium using the graphs given in Fig. 7 are given in Table 2 in conjunction with the relevant correlation coefficients.

The values of the correlation coefficients $\left(R^{2}\right)$ determined for the pseudo first order kinetic model are low for the studied three different initial arsenate concentrations as shown in Table 2. Similarly, the experimental $q_{e}$ (exp) values are not compatible with the theoretical $q_{e}$ (cal) values calculated using pseudo first order kinetic model equations. These results demonstrated that the pseudo first order kinetic model might not suitable and adequate to define the mechanism of arsenate adsorption on GOFeZA and GOFeZB composites. At the same time, the $K_{1}$ values given in Table 2 show that the change of the initial arsenate concentration does not significantly affect the adsorption rate constant. The values of $q_{e}$ (cal) at the equilibrium were the highest for GOFeZB at the initial arsenate concentration of $50 \mu \mathrm{g} / \mathrm{L}$ and the highest for GOFeZA at initial arsenate
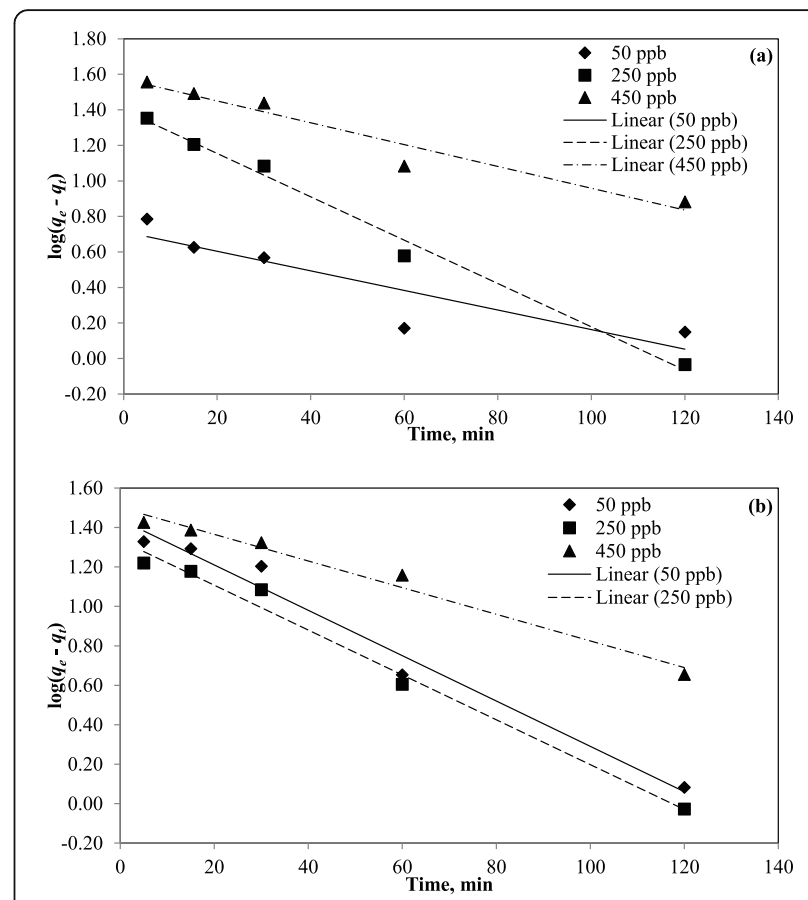

Fig. 7 Pseudo first order kinetic model for arsenate adsorption a GOFeZA and $\mathbf{b}$ GOFeZB

concentrations of 250 and $450 \mu \mathrm{g} / \mathrm{L}$, although the $R^{2}$ values indicated that the pseudo first order kinetic model did not represent the experimental results well. This result shows that the $q_{e}$ (cal) value is influenced not only by the initial arsenate concentration but also by the amount of FeZ in the composite material. In addition, when the $K_{1}$ values were examined for all initial concentrations, it was observed that arsenate adsorption on GOFeZB was faster at low initial arsenate concentration $(50 \mu \mathrm{g} / \mathrm{L})$, while arsenate adsorption on GOFeZA was faster at high initial arsenate concentrations.

Another most commonly used kinetic model, the pseudo second order kinetic model, is defined by the following equation:

$$
\frac{t}{q_{t}}=\frac{1}{K_{2} q_{e}^{2}}+\frac{t}{q_{e}}
$$

where $K_{2}(\mathrm{~g} / \mu \mathrm{g} \mathrm{min})$ is the rate constant for the pseudo second order kinetic model. The graphs of $t$ versus $t / q_{t}$ for GOFeZA and GOFeZB are given in Fig. 8a, b. The values of the $q_{e}$ (cal) and $K_{2}$ were determined using the slope and intercept of the line, respectively, and the results are shown in Table 2. The values of $R^{2}$ obtained from the pseudo second order kinetic models were found to be above 0.99 for both composite materials, and these $R^{2}$ values were higher than the values determined for the pseudo first order kinetic model. Also, the theoretical $q_{e}$ (cal) values and the experimental $q_{e}$ 
Table 2 The parameters of pseudo first order and second order kinetic model for arsenate adsorption on GOFeZA and GOFeZB

\begin{tabular}{|c|c|c|c|c|c|c|c|}
\hline \multirow{2}{*}{$\begin{array}{l}C_{0} \\
(\mu g / \\
L) \\
\end{array}$} & \multirow{2}{*}{$\begin{array}{l}q_{e} \\
(\exp ) \\
(\mu \mathrm{g} / \mathrm{g})\end{array}$} & \multicolumn{3}{|c|}{ Pseudo first order kinetic model } & \multicolumn{3}{|c|}{ Pseudo second order kinetic model } \\
\hline & & $\overline{K_{1}(1 / \min )}$ & $q_{e}(\mathrm{cal})(\mu \mathrm{g} / \mathrm{g})$ & $R^{2}$ & $\overline{K_{2}(\mathrm{~g} / \mu \mathrm{g} \min )}$ & $q_{e}(\mathrm{cal})(\mu \mathrm{g} / \mathrm{g})$ & $R^{2}$ \\
\hline \multicolumn{8}{|c|}{ GOFeZA } \\
\hline 50 & 60.458 & 0.0263 & 5.171 & 0.8011 & 0.0206 & 59.524 & 0.9999 \\
\hline 250 & 310.106 & 0.0421 & 25.045 & 0.9910 & 0.0038 & 312.500 & 0.9999 \\
\hline 450 & 557.856 & 0.0291 & 37.446 & 0.9430 & 0.0025 & 555.556 & 0.9999 \\
\hline \multicolumn{8}{|c|}{ GOFeZB } \\
\hline 50 & 59.854 & 0.0308 & 27.568 & 0.9783 & 0.0022 & 61.728 & 0.9999 \\
\hline 250 & 306.128 & 0.0410 & 21.612 & 0.9874 & 0.0042 & 303.030 & 0.9999 \\
\hline 450 & 554.641 & 0.0316 & 31.681 & 0.9804 & 0.0025 & 555.556 & 0.9999 \\
\hline
\end{tabular}

(exp) values were very close to each other in pseudo second order kinetic model. Therefore, it was concluded that the pseudo second order kinetic model provides a very good correlation in arsenate adsorption on GOFeZA and GOFeZB. Consequently, arsenate adsorption on GOFeZA and GOFeZB was better explained by rate-controlled kinetics and arsenate adsorption is controlled by the presence of the surface areas on GOFeZA and GOFeZB rather than by arsenate concentration in aqueous solution (Lingamdinne et al. 2019; Yoon et al. 2017).

Considering the equilibrium $q_{e}$ (cal) values, GOFeZA and GOFeZB adsorbed the highest amount of arsenate from the aqueous solution at high and low initial
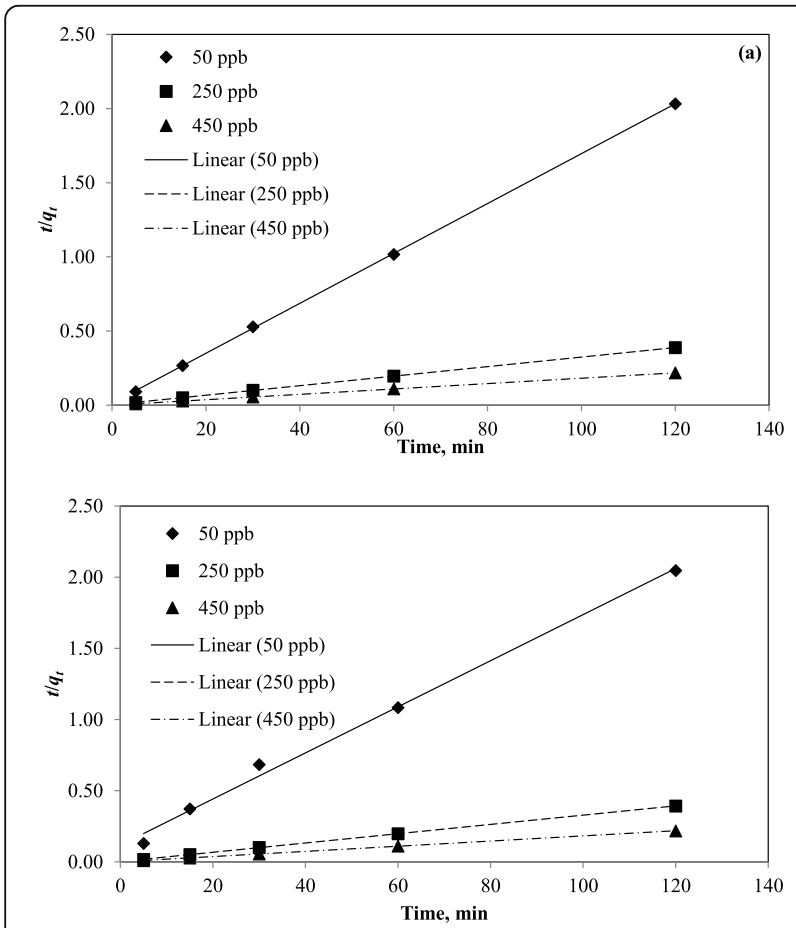

Fig. 8 Pseudo second order kinetic model for arsenate adsorption a GOFeZA and $\mathbf{b}$ GOFeZB arsenate concentration, respectively. The same result was obtained from the first order kinetic model. While the $K_{2}$ parameter was the highest value in the case of using GOFeZA composite for the $50 \mu \mathrm{g} / \mathrm{L}$ of initial arsenate concentration, these values were very close in both composites at the high initial arsenate concentrations.

The pseudo second order kinetic model has been determined as the most suitable model for defining the arsenate adsorption kinetics from aqueous solutions for different GO-based composite materials such as fly ashbased zeolite-rGO (Soni and Shukla 2019), mesoporous GO-lanthanum fluoride (Lingamdinne et al. 2019), $\mathrm{Fe}_{3} \mathrm{O}_{4}$-graphene macroscopic composites (Guo et al. 2015), graphene-zeolite based composites (Khatamian et al. 2017), and magnetite/non-oxidative graphene composites (Yoon et al. 2017).

\section{Adsorption mechanism}

In order to reveal the arsenate adsorption mechanism on GOFeZA and GOFeZB, SEM, EDS, and FTIR analyses of the composites were performed after arsenate adsorption. As shown in Fig. 9a, b, a noticeable alteration was observed in the structure and morphology of the composites after arsenate adsorption. After loading the arsenate onto the surface of the composites, it is obviously distinguished that a thin layer of arsenate was formed on the surface of the composites; the crystals became embedded in the surface and the surface became smoothened. This could indicate that the composites react effectively with arsenate ions in the aqueous solution. In accordance with these results, the presence of $\mathrm{C}$, $\mathrm{O}, \mathrm{Fe}, \mathrm{Al}, \mathrm{Si}$, and $\mathrm{As}$ is also observed in the EDS spectrum obtained after arsenate adsorption of composites as shown in Fig. 9a, b. The arsenic peaks only observed in the EDS spectra obtained after the arsenate adsorption of the composites indicate the adsorbed arsenate on the surfaces of the composite. In addition, while the composite surfaces were loaded with arsenate, there was no remarkable loss in other elements. 


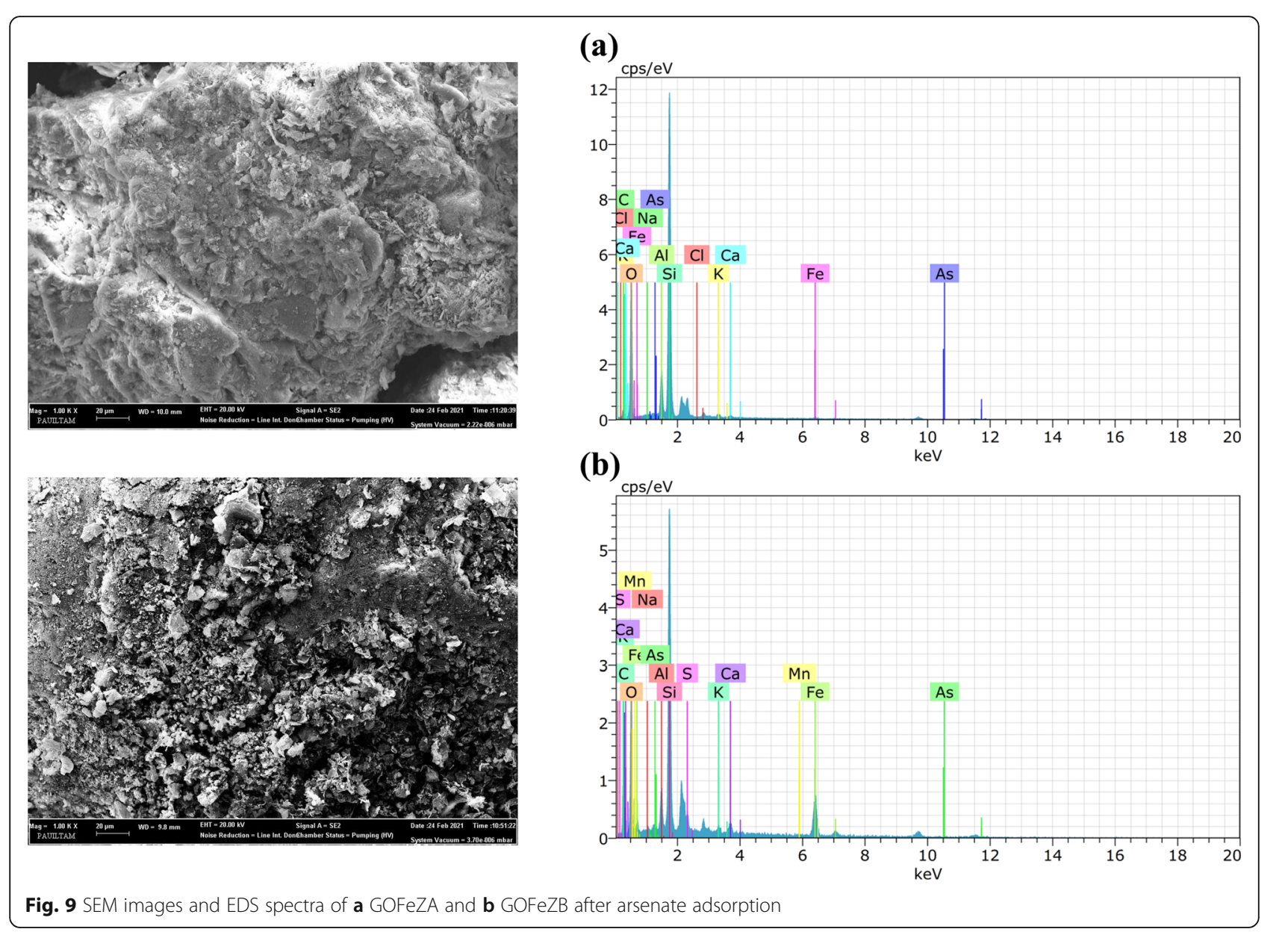

According to the FTIR data obtained after arsenate adsorption on composites given in Figure S1(a-b), the O-H group for GOFeZA shifted from 3342 to $3368 \mathrm{~cm}^{-1}$ and for GOFeZB from 3341 to $3379 \mathrm{~cm}^{-1}$. Similarly, the peak indicating the aromatic $\mathrm{C}=\mathrm{C}$ group shifted from 1614 to $1557 \mathrm{~cm}^{-1}$ for GOFeZA and from 1621 to $1558 \mathrm{~cm}^{-1}$ for GOFeZB. In other groups such as $\mathrm{C}=\mathrm{O}, \mathrm{C}-\mathrm{O}$ group related carboxyl to and $\mathrm{C}-\mathrm{O}$ group related to epoxy, no significant change was observed after arsenate adsorption. These results imply the efficiency of $\mathrm{O}-\mathrm{H}$ and aromatic $\mathrm{C}=\mathrm{C}$ groups in arsenate adsorption. The characteristic peaks expressing the stretching vibration of the T-O bands due to the structure of the clinoptilolite and observed for GOFeZA at 591, 677, and 1021 $\mathrm{cm}^{-1}$ before arsenate adsorption were observed at 437, 593 , and $1039 \mathrm{~cm}^{-1}$ after adsorption, respectively. The mentioned peaks observed at 602,660 , and $1015 \mathrm{~cm}^{-1}$ for GOFeZB before adsorption were similarly observed at 597,672 , and $1034 \mathrm{~cm}^{-1}$ after adsorption, respectively. The results obtained from the all characterization studies of composites performed after arsenate adsorption suggest that surface complexation and/or ion exchange processes are effective mechanisms in arsenate adsorption on the surface of the composites. Similar results were obtained from different studies on arsenic adsorption from aqueous solutions (Memon et al. 2021; Lingamdinne et al. 2019). Furthermore, the results obtained from the $\mathrm{pH}_{\mathrm{pzc}}$ studies and adsorption kinetics studies of the composites demonstrated the effectiveness of the surface complexation and/or ion exchange processes as well as the electrostatic interaction in the arsenate adsorption on the composites.

\section{Results of arsenate uptake by fixed-bed column tests}

According to the results of the batch adsorption experiments and kinetic studies, although the time to reach equilibrium of both composite adsorbents was the same and both adsorbents could reduce the arsenate concentration in the solution below $10 \mu \mathrm{g} / \mathrm{L}$, which is the MCL for arsenic in drinking water as determined by WHO, it was observed that GOFeZA had a slightly higher adsorption capacity at the equilibrium than GOFeZB. It was also demonstrated that the GOFeZA removed arsenic from the aqueous solution with higher efficiency at the both low and high initial arsenate concentrations and at the end of the equilibrium period. Besides the results of 
these adsorption studies, the fact that GOFeZB material contains two times more treated clinoptilolite (FeZ) than GOFeZA indicated that the obtaining conditions and economy of GOFeZB are more challenging. In the light of these results and considering the preparation procedure of the composites, it was decided to perform continuous adsorption experiments using GOFeZA.

\section{Influence of flow rate on arsenate uptake}

The flow rate of the solution passed through the fixedbed column is one of the important parameters affecting the breakthrough point, mass transfer rate, and efficiency of the system in continuous adsorption experiments (Patel 2019). In this study, continuous adsorption experiments were carried out at two different flow rates, $1.7 \mathrm{~mL} / \mathrm{min}$ and $2.0 \mathrm{~mL} / \mathrm{min}$, to determine the influence of the flow rate on the system. The flow rates were controlled by collecting the effluent from the column for a specified time and measuring the collected effluent volume. The arsenate concentration in the water passed through the column was prepared as $100 \mu \mathrm{g} / \mathrm{L}$ and the $\mathrm{pH}$ value of the solution was adjusted to 7 as in the batch experiments. The impact of the flow rate on breakthrough point under the mentioned operating conditions is given in Fig. 10, as it can be observed from the figure that the effectiveness of arsenate adsorption is higher when the flow rate is low. This is due to the fact that GOFeZA has more contact time with the arsenate solution at the lower flow rate. Therefore, it can be concluded that the arsenate ions in the solution need a low flow rate and consequently more time to effectively adhere to the GOFeZA. Increasing the flow rate accelerates the saturation of the breakthrough time and increases the length of the mass transfer zone (Patel 2019; LopezCervantes et al. 2018). It has been reported by other researchers that at low flow rates, the pollutant is in contact with the adsorbent for a longer time, and therefore higher removal of the pollutant is achieved in the column (Ahmad and Hameed 2009; Sheng et al. 2018).

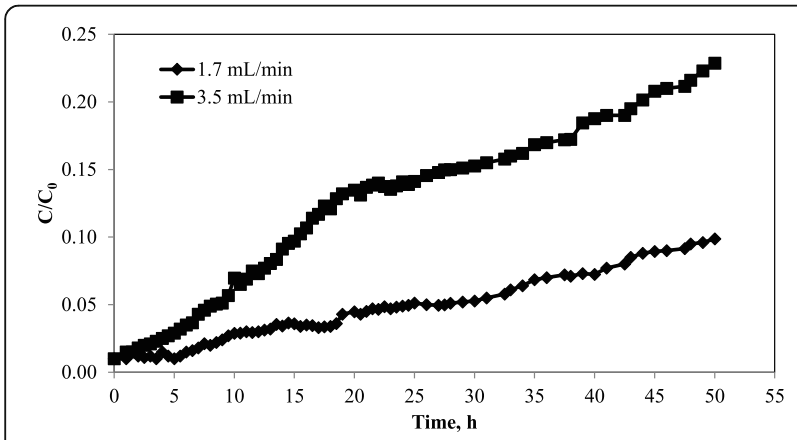

Fig. 10 Flow rate effect on breakthrough time in the fixed-bed column study using fresh GOFeZA
The values of the empty bed contact time (EBCT), breakthrough time, volume of treated water, and surface loading rate obtained and calculated as a result of fixedbed column tests performed at flow rates of $1.7 \mathrm{~mL} / \mathrm{min}$ and $3.5 \mathrm{~mL} / \mathrm{min}$ are shown in Table 3 . The increasing the flow rate of the arsenate solution through the column resulted in a decrease in EBCT, breakthrough time, and volume of purified water. This tendency might be due to the increase in the retention time of the arsenate ions in the bed required for more arsenate ions to attach to the pores of GOFeZA and thus increase the arsenate uptake efficiency (Dhoble et al. 2017). In addition, the turbulence caused by the increased flow rate may have caused the interaction time between the GOFeZA and arsenate ions in the solution to decrease (Zhu et al. 2018; Russo et al. 2016; Sun et al. 2017). In this study, due to the reduction of the flow rate from $3.5 \mathrm{~mL} / \mathrm{min}$ to $1.7 \mathrm{~mL} / \mathrm{min}$, an increase occurred in the breakthrough time of about $213 \%$, the volume of treated water of $52 \%$, and the EBCT of $107 \%$. Another reason for the effect of increased flow rate on the breakthrough time, volume of treated water, and EBCT could be that the reduced contact time causes poor dispersion of the solution in the column, resulting in less diffusivity of arsenate ions in solution onto GOFeZA (Dhoble et al. 2017).

\section{Regeneration study}

The regeneration of the fixed-bed column reactor was carried out to evaluate the possibility for the reuse of GOFeZA to remove arsenate ions from the water after it was exhausted. Regeneration and reuse of the adsorbent during many cycles of the treatment, both the disposal difficulty of the adsorbent and the replacement of the new one are an important economic indicator and essential aspect of the feasibility of the adsorption process (Lata et al. 2015; Dhoble et al. 2017). Among the various regeneration methods with different advantages and disadvantages, chemical regeneration stands out due to its high efficiency and speed of regeneration and low energy requirement (Ghasemzadeh et al. 2017; Larasati et al. 2020). Environmental condition-occurred adsorption is of great importance in determining the solution to be used in chemical regeneration (Larasati et al. 2020). In the regeneration of GOFeZA, the solution of $0.1 \mathrm{M}$ $\mathrm{NaOH}$ was passed through the exhausted fixed-bed column at the flow rate of $1.7 \mathrm{~mL} / \mathrm{min}$ in downflow mode. Distilled water was passed through the column until the $\mathrm{pH}$ of the effluent was neutral, before the fixed-bed column was used again for the purification of the solution containing $100 \mu \mathrm{g} / \mathrm{L}$ of arsenate. Figure 11 shows the breakthrough curve for fresh and regenerated GOFeZA. As a result of the continuous operated column study with regenerated GOFeZA, it was demonstrated that the breakthrough time was $14.5 \mathrm{~h}$ and the volume of treated 
Table 3 Effect of different flow rate on important operating parameters of continuous column tests using GOFeZA

\begin{tabular}{lllll}
\hline Flow rate $(\mathbf{m L} / \mathbf{m i n})$ & EBCT $(\mathbf{m i n})$ & Breakthrough time $(\mathbf{h})$ & Volume of treated water $(\mathrm{L})$ & Surface loading rate $\left(\mathrm{mL} / \mathrm{cm}^{\mathbf{2}} \mathbf{m i n}\right)$ \\
\hline 1.7 & 28.0 & 25.0 & 2.55 & 0.54 \\
3.5 & 13.5 & 8.0 & 1.68 & 1.12 \\
\hline
\end{tabular}

water was approximately $1.5 \mathrm{~L}$. Therefore the regenerated GOFeZA has lower breakthrough time and volume of treated water compared to fresh GOFeZA. The breakthrough time and volume of treated water of regenerated GOFeZA were decreased about $58 \%$ and $58 \%$, respectively. Dhoble et al. (2017) has found similar results in arsenite removal with magnetic binary oxide particles. This result shows that even though there was a decrease in the arsenate adsorption effectiveness of GOFeZA after regeneration, still significant adsorption efficiency was taken place.

\section{Conclusions}

In the present study, arsenate adsorption from aqueous solution was carried out using the composite materials of GOFeZA and GOFeZB formed by combining two different materials with superior properties. The SEM images and the XRF data of GOFeZA and GOFeZB revealed that the presence of iron on the composites and FeZ particles were spread overall the GO. In addition, the EDS diagrams of GOFeZA and GOFeZB demonstrate the successful formation of composites because they contain elements such as $\mathrm{Al}, \mathrm{Si}$, and $\mathrm{Fe}$ in $\mathrm{FeZ}$ and elements such as carbon and oxygen, which indicate the presence of GO. The EDS spectra and XRF data of the composites also prove that more $\mathrm{FeZ}$ was used in the process of the obtaining composite of GOFeZB. The FTIR spectrum of the composites shows that the composites were synthesized accomplishedly using GO and FeZ. The results of the batch experiments showed that the both composites were able to reduce the residual arsenate concentration in water below $10 \mu \mathrm{g} / \mathrm{g}$, MCL set by the WHO, at the equilibrium for three different initial arsenate concentrations. The adsorption process was explained by the surface complexation or ion exchange

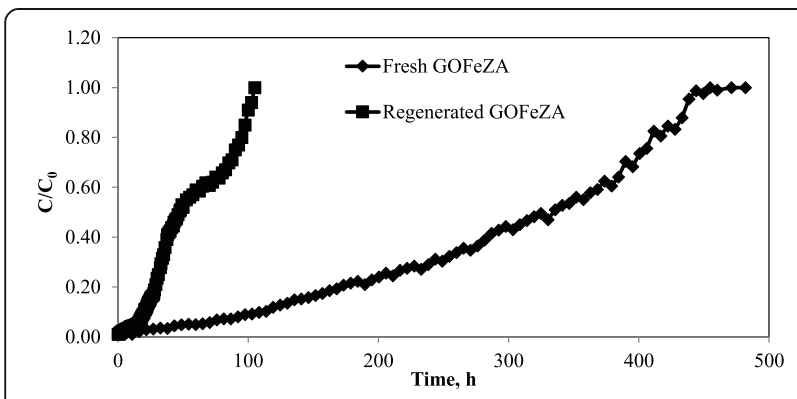

Fig. 11 Fixed-bed column study on fresh and regenerated GOFeZA and electrostatic attraction between GOFeZA or GOFeZB and arsenate ions in the aqueous solution due to the relatively low equilibrium time and fairly rapid adsorption of arsenate at the beginning of the process. Furthermore, the results obtained from the all characterization studies of composites performed after arsenate adsorption and $\mathrm{pH}_{\mathrm{pzc}}$ studies of adsorbents suggest that not only electrostatic interaction but also ion exchange and surface complexation are effective in arsenate adsorption on composites. The adsorption capacity increases with the increase of the initial arsenate concentration for both composites at equilibrium. At the initial arsenate concentration of $450 \mu \mathrm{g} / \mathrm{L}$, the arsenate adsorption on GOFeZA and GOFeZB was 557.86 and $554.64 \mu \mathrm{g} / \mathrm{g}$, respectively. The pseudo second order kinetic model provided a very good correlation in arsenate adsorption on GOFeZA and GOFeZB according to the $R^{2}$ values and $q_{e}(\exp )$ and $q_{e}$ (cal) values, which are very close to each other. Therefore, it was concluded that the arsenate adsorption on GOFeZA and GOFeZB was better explained by rate-controlled kinetics and arsenate adsorption is controlled by the presence of the surface areas on GOFeZA and GOFeZB rather than by arsenate concentration in aqueous solution.

According to the results of the batch adsorption experiments and kinetic studies, the continuous adsorption experiments were performed using GOFeZA. The fixedbed column experiments showed that the effectiveness of arsenate adsorption is higher when the flow rate is low. The increasing the flow rate of the arsenate solution through the column resulted in a decrease in EBCT, breakthrough time and volume of treated water. As a result of the continuous operation column study with regenerated GOFeZA, it was demonstrated that the regenerated GOFeZA has lower breakthrough time and volume of treated water compared to fresh GOFeZA. But still significant adsorption efficiency occurred. Therefore, this study demonstrates the potential for probable application of GOFeZA for arsenate removal from aqueous solutions.

\footnotetext{
Abbreviations

WHO: World Health Organization; GO: Graphene oxide; rGO: Reduced graphene oxide; FeZ: Iron modified clinoptilolite; GOFeZA: The composite material formed by taking $2 \mathrm{~g}$ of $\mathrm{GO}$ and $2 \mathrm{~g}$ of FeZ; GOFeZB: The composite material obtained by taking $2 \mathrm{~g}$ of $\mathrm{GO}$ and $4 \mathrm{~g}$ of FeZ; SEM: Scanning electron microscopy; XRF: X-ray fluorescence spectrometry; ICP-MS: Inductively coupled plasma-mass spectrometer; MCL: Maximum contaminant level; $R^{2}$ : Correlation coefficients; EBCT: Empty bed contact time
} 


\section{Supplementary Information}

The online version contains supplementary material available at https://doi. org/10.1186/s40543-021-00274-6.

Additional file 1: Figure S1. FTIR spectra of composites before and after arsenate adsorption.

\section{Acknowledgements}

Not applicable in this section.

\section{Authors' contributions}

MBB: Conceptualization (lead), investigation (lead), writing-original draft (lead), writing-review and editing (lead), experimental design (lead), methodology (lead), project administration (lead), and interpretation of data (lead). SH: Conceptualization (supported), investigation (supporting), and conducting experiments (lead). Both authors read and approved the final manuscript.

\section{Funding}

This work was supported by the Scientific Research Projects of the Pamukkale University, Denizli, Turkey, under grant number 2018 FEBE047.

\section{Availability of data and materials}

The data that support the findings of this study are available from the corresponding author upon reasonable request.

\section{Declarations}

\section{Competing interests}

The authors declare that they have no competing interest.

\section{Author details}

${ }^{1}$ Department of Environmental Engineering, Pamukkale University, 20160 Denizli, Turkey. ${ }^{2}$ Department of Environmental Protection and Control, Denizli Metropolitan Municipality, Denizli, Turkey.

Received: 25 January 2021 Accepted: 9 April 2021

Published online: 22 April 2021

\section{References}

Abaei Z, Faghihian H, Esmaeeli N. Preparation and application of zeolitic adsorbents for removal of fuoride from aqueous solution; equilibrium, kinetic and thermodynamic studies. Der Chemica Sinica. 2017:8:524-34.

Adane T, Haile D, Dessie A, Abebe Y, Dagne H. Response surface methodology as a statistical tool for optimization of removal of chromium (VI) from aqueous solution by Teff (Eragrostis teff) husk activated carbon. App Water Sci. 2020; 10:1-13.

Ahmad AA, Hameed BH. Fixed-bed adsorption of reactive azo dye onto granular activated carbon prepared from waste. J Hazard Mater. 2009;175:298-303.

Amen R, Bashir H, Bibi I, Shaheen SM, Niazi NK, Shahid M, et al. A critical review on arsenic removal from water using biochar-based sorbents: the significance of modification and redox reactions. Chem Eng J. 2020:396: 125195. https://doi.org/10.1016/j.cej.2020.125195.

Asere TG, Stevens CV, Laing GD. Use of (modified) natural adsorbents for arsenic remediation: a review. Sci Total Environ. 2019;676:706-20. https://doi.org/10.1 016/j.scitotenv.2019.04.237.

Bian Y, Bian ZY, Zhang JX, Ding AZ, Liu SL, Wang H. Effect of the oxygencontaining functional group of graphene oxide on the aqueous cadmium ions removal. Appl Surf Sci. 2015;329:269-75. https://doi.org/10.1016/j.a psusc.2014.12.090.

Bilici Baskan M, Hadimlioglu S. Graphene oxide-iron modified clinoptilolite based composites for adsorption of arsenate and optimization using response surface methodology. J Environ Sci Health A. 2021:1-12. https://doi.org/10.1 080/10934529.2021.1894041.

Bilici Baskan M, Pala A. A statistical experiment design approach for arsenic removal by coagulation process using aluminum sulfate. Desalination. 2010; 254(1-3):42-8. https://doi.org/10.1016/j.desal.2009.12.016.

Bilici Baskan M, Pala A. Removal of arsenic from drinking water using modified natural zeolite. Desalination. 2011;281:396-403. https://doi.org/10.1016/j.desa I.2011.08.015
Bora AJ, Gogoi S, Baruah G, Dutta RK. Utilization of co-existing iron in arsenic removal from groundwater by oxidation-coagulation at optimized $\mathrm{pH}$. J Environ Chem Eng. 2016;4(3):2683-91. https://doi.org/10.1016/j.jece.2016.05. 012.

Bretzler A, Nikiema J, Lalanne F, Hoffmann L, Biswakarma J, Siebenaller L, et al. Arsenic removal with zero-valent iron filters in Burkina Faso: field and laboratory insights. Sci Total Environ. 2020;737:139466. https://doi.org/10.101 6/j.scitotenv.2020.139466.

Cortes-Arriagada D, Toro-Labbe A. Aluminum and iron doped graphene for adsorption of methylated arsenic pollutants. Appl Surf Sci. 2016;386:84-95. https://doi.org/10.1016/j.apsusc.2016.05.154.

Das TK, Sakthivel TS, Jeyaranjan A, Seal S, Bezbaruah AN. Ultra-high arsenic adsorption by graphene oxide iron nanohybrid: removal mechanisms and potential applications. Chemosphere. 2020;253:126702. https://doi.org/10.101 6/j.chemosphere.2020.126702

Dhoble RM, Maddigapu PR, Rayalu SS, Bhole AG, Dhoble AS, Dhoble SR. Removal of arsenic(III) from water by magnetic binary oxide particles (MBOP): experimental studies on fixed bed column. J Hazard Mater. 2017;322(Pt B): 469-78. https://doi.org/10.1016/j.jhazmat.2016.09.075.

Figueiredo H, Quintelas C. Tailored zeolites for the removal of metal oxyanions: overcoming intrinsic limitations of zeolites. J Hazard Mater. 2014:274:287-99. https://doi.org/10.1016/j.jhazmat.2014.04.012.

Ghasemzadeh N, Ghadiri M, Behroozsarand A. Optimization of chemical regeneration procedures of spent activated carbon. Adv Environ Tech. 2017; 1:45-51.

Goren AY, Kobya M. Arsenic removal from groundwater using an aerated electrocoagulation reactor with 3D Al electrodes in the presence of anions. Chemosphere. 2021;263:128253. https://doi.org/10.1016/j.chemosphere.202 0.128253.

Guaya D, Valderrama C, Farrana A, Cortinaa UL. Modification of a natural zeolite with $\mathrm{Fe}(\mathrm{III})$ for simultaneous phosphate and ammonium removal from aqueous solutions. J Chem Technol Biotechnol. 2016;91(6):1737-46. https:// doi.org/10.1002/jctb.4763

Guo H, Stüben D, Berner Z. Adsorption of arsenic(III) and arsenic(V) from groundwater using natural siderite as the adsorbent. J Colloid Interface Sci. 2007;315(1):47-53. https://doi.org/10.1016/j.jcis.2007.06.035.

Guo L, Ye P, Wang J, Fu F, Wu Z. Three-dimensional Fe3O4-graphene macroscopic composites for arsenic and arsenate removal. J Hazard Mater. 2015;298:28-35. https://doi.org/10.1016/j.jhazmat.2015.05.011.

Hashim MA, Kundu A, Mukherjee S, Ng YS, Mukhopadhyay S, Redzwan G, et al. Arsenic removal by adsorption on activated carbon in a rotating packed bed. J Water Process Eng. 2019;30:100591. https://doi.org/10.1016/j.jwpe.2018.03. 006

Ho YS. Citation review of Lagergren kinetic rate equation on adsorption reactions. Scientometrics. 2004;59:171-7.

Huang T, Yan M, He K, Huang Z, Zeng G, Chen A, et al. Efficient removal of methylene blue from aqueous solutions using magnetic graphene oxide modified zeolite. J Colloid Interface Sci. 2019;543:43-51. https://doi.org/10.1 016/j.jcis.2019.02.030

Hummers WS, Offeman RE. Preparation of graphitic oxide. J Am Chem Soc. 1958; 80(6):1339. https://doi.org/10.1021/ja01539a017.

Khatamian M, Khodakarampoor N, Saket-Oskoui M. Efficient removal of arsenic using graphene-zeolite based composites. J Colloid Interface Sci. 2017:498: 433-41. https://doi.org/10.1016/j.jcis.2017.03.052.

Kloster GA, Valiente M, Marcovich NE, Mosiewicki MA. Adsorption of arsenic onto films based on chitosan and chitosan/nano-iron oxide. Int J Biol Macromol. 2020;165(Pt A):1286-95. https://doi.org/10.1016/j.ijbiomac.2020.09.244.

Kobya M, Soltani RDC, Omwene PI, Khataee A. A review on decontamination of arsenic-contained water by electrocoagulation: reactor configurations and operating cost along with removal mechanisms. Environ Technol Innov. 2020;17:100519. https://doi.org/10.1016/j.eti.2019.100519.

Kundu S, Kavalakatt SS, Pal A, Ghosh SK, Mandal M, Pal T. Removal of arsenic using hardened paste of Portland cement: batch adsorption and column study. Water Res. 2004;38(17):3780-90. https://doi.org/10.1016/j.watres.2004. 06.018

Larasati A, Fowler GD, Graham NJD. Chemical regeneration of granular activated carbon: preliminary evaluation of alternative regenerant solutions. Environ Sci Water Res Technol. 2020:8:2043-56.

Lata S, Singh PK, Samadder SR. Regeneration of adsorbents and recovery of heavy metals: a review. Int J Environ Sci Technol. 2015;12(4):1461-78. https:// doi.org/10.1007/s13762-014-0714-9. 
Lee CG, Alvarez PJJ, Nam A, Park SJ, Do T, Choi US, et al. Arsenic(V) removal using an amine-doped acrylic ion exchange fiber: kinetic, equilibrium, and regeneration studies. J Hazard Mater. 2017;325:223-9. https:/doi.org/10.1016/j.jhazmat.2016.12.003.

Li Z, Wu L, Sun S, Gao J, Zhang H, Zhang Z, et al. Disinfection and removal performance for Escherichia coli, toxic heavy metals and arsenic by wood vinegar-modified zeolite. Ecotoxicol Environ Saf. 2019;174:129-36. https://doi. org/10.1016/j.ecoenv.2019.01.124.

Lingamdinne LP, Koduru JR, Chang YY, Kang SH, Yang JK. Facile synthesis of flowered mesoporous graphene oxide-lanthanum fluoride nanocomposite for adsorptive removal of arsenic. J Mol Liq. 2019;279:32-42. https://doi.org/1 0.1016/j.molliq.2019.01.103.

Lopez-Cervantes J, Sanchez-Machado DI, Sanchez-Duarte RG, Correa-Murrieta MA. Study of a fixed-bed column in the adsorption of an azo dye from an aqueous medium using a chitosan-glutaraldehyde biosorbent. Adsorp Sci Technol. 2018;36:215-32.

Luo X, Wang C, Luo S, Dong R, Tu X, Zeng G. Adsorption of As (III) and As (V) from water using magnetite $\mathrm{Fe}_{3} \mathrm{O}_{4}$-reduced graphite oxide- $\mathrm{MnO}_{2}$ nanocomposites. Chem Eng J. 2012;187:45-52.

Luo X, Wang C, Wang L, Deng F, Luo S, Tu X, et al. Nanocomposites of graphene oxide-hydrated zirconium oxide for simultaneous removal of As(III) and As( () from water. Chem Eng J. 2013;220:98-106. https://doi.org/10.1016/j.cej.2013.01.017.

Memon AQ, Ahmed S, Bhatti ZA, Maitlo G, Shah AK, Mazari SA, et al. Experimental investigations of arsenic adsorption from contaminated water using chemically activated hematite $\left(\mathrm{Fe}_{2} \mathrm{O}_{3}\right)$ iron ore. Environ Sci Pollut Res. 2021;28(10):12898-908. https://doi.org/10.1007/s11356-020-11208-x.

Mohan D, Pittman CU Jr. Arsenic removal from water/wastewater using adsorbents-A critical review. J Hazard Mater. 2007;142(1-2):1-53. https://doi. org/10.1016/j.jhazmat.2007.01.006

Nguyen VT, Vigneswaran S, Ngo HH, Shon HK, Kandasamy J. Arsenic removal by a membrane hybrid filtration system. Desalination. 2009;236(1-3):363-9. https://doi.org/10.1016/j.desal.2007.10.088.

Ochedi FO, Liu Y, Hussain A. A review on coal fly ash-based adsorbents for mercury and arsenic removal. J Clean Prod. 2020;267:122143. https://doi. org/10.1016/j.jclepro.2020.122143.

Okoli J, Ezuma I. Adsorption studies of heavy metals by low-cost adsorbents. J Appl Sci Environ Manage. 2014;18:443-8.

Pallier V, Feuillade-Cathalifaud G, Serpaud B, Bollinger JC. Effect of organic matter on arsenic removal during coagulation/flocculation treatment. J Colloid Interface Sci. 2010;342(1):26-32. https://doi.org/10.1016/j.jcis.2009.09.068.

Pang D, Wang CC, Wang P, Liu W, Fu H, Zhao C. Superior removal of inorganic and organic arsenic pollutants from water with MIL-88A(Fe) decorated on cotton fibers. Chemosphere. 2020;254:126829.

Patel H. Fixed-bed column adsorption study: a comprehensive review. Appl Water Sci. 2019;9:1-17.

Rodriguez C, Tapia C, Leiva-Aravena E, Leiva E. Graphene Oxide-ZnO nanocomposites for removal of aluminum and copper ions from acid mine drainage wastewater. Int J Environ Res Public Health. 2020;17(18):6911. https://doi.org/10.3390/ijerph17186911.

Roy P, Mondal NK, Bhattacharya S, Das B, Das K. Removal of arsenic(III) and arsenic(V) on chemically modified low-cost adsorbent: batch and column operations. Appl Water Sci. 2013;3(1):293-309. https:/doi.org/10.1007/s13201-013-0082-5.

Ruiz-Baltazar A, Esparza R, Gonzalez M, Rosas G, Perez R. Preparation and characterization of natural zeolite modified with iron nanoparticles. J Nanomater. 2015;2015:364763.

Russo V, Masiello D, Trifuoggi M, Serio MD, Tesser R. Design of an adsorption column for methylene blue abatement over silica: from batch to continuous modeling. Chem Eng J. 2016;302:287-95. https://doi.org/10.1016/j.cej.2016.05.020.

Schmidt SA, Gukelberger E, Hermann M, Fiedler F, Großmann B, Hoinkis J, et al. Pilot study on arsenic removal from groundwater using a small-scale reverse osmosis system — towards sustainable drinking water production. J Hazard Mater. 2016;318:671-8. https://doi.org/10.1016/j.jhazmat.2016.06.005.

Sheng L, Zhang Y, Tang F, Liu S. Mesoporous/microporous silica materials: preparation from natural sands and highly efficient fixed-bed adsorption of methylene blue in wastewater. Microporous Mesoporous Mater. 2018;257:918. https://doi.org/10.1016/j.micromeso.2017.08.023.

Sherlala AIA, Raman AAA, Bello MM, Buthiyappan A. Adsorption of arsenic using chitosan magnetic graphene oxide nanocomposite. J Environ Manage. 2019; 246:547-56. https://doi.org/10.1016/j.jenvman.2019.05.117.

Simsek EB, Özdemir E, Beker U. Zeolite supported mono- and bimetallic oxides: promising adsorbents for removal of $\mathrm{As}(\mathrm{V})$ in aqueous solutions. Chem Eng J. 2013;220:402-11. https://doi.org/10.1016/j.cej.2013.01.070.
Singh S, Rathi K, Pal K. Synthesis, characterization of graphene oxide wrapped silicon carbide for excellent mechanical and damping performance for aerospace application. J Alloys Compd. 2018;740:436-45. https://doi.org/10.1 016/j.jallcom.2017.12.069.

Singh TS, Pant KK. Experimental and modelling studies on fixed bed adsorption of As(III) ions from aqueous solution. Sep Purif Technol. 2006;48(3):288-96. https://doi.org/10.1016/j.seppur.2005.07.035.

Smedley PL, Kinniburgh DG. A review of the source, behaviour and distribution of arsenic in natural waters. Appl Geochem. 2002;17(5):517-68. https://doi. org/10.1016/S0883-2927(02)00018-5.

Soni R, Shukla DP. Synthesis of fly ash based zeolite-reduced graphene oxide composite and its evaluation as an adsorbent for arsenic removal. Chemosphere. 2019;219:5049. https:/doi.org/10.1016/j.chemosphere.2018.11.203.

Su H, Ye Z, Hmidi N. High-performance iron oxide-graphene oxide nanocomposite adsorbents for arsenic removal. Colloids Surf A Physicochem Eng Asp. 2017;522:161-72. https://doi.org/10.1016/j.colsurfa.2017.02.065.

Sun C, Xiong B, Pan Y, Cui H. Adsorption removal of tannic acid from aqueous solution by polyaniline: analysis of operating parameters and mechanism. J Colloid Interface Sci. 2017;487:175-81. https://doi.org/10.1016/j.jcis.2016.10.035.

Tasharrofi S, Rouzitalab Z, Maklavany DM, Esmaeili A, Rabieezadeh M, Askarieh M, et al. Adsorption of cadmium using modified zeolite-supported nanoscale zero-valent iron composites as a reactive material for PRBs. Sci Total Environ. 2020;736:139570. https://doi.org/10.1016/j.scitotenv.2020.139570.

Tripathy SS, Raichur AM. Enhanced adsorption capacity of activated alumina by impregnation with alum for removal of $\mathrm{As}(\mathrm{V})$ from water. Chem Eng J. 2008; 138(1-3):179-86. https://doi.org/10.1016/j.cej.2007.06.028.

Urbano BF, Rivas BL, Martinez F, Alexandratos SD. Water-insoluble polymer-clay nanocomposite ion exchange resin based on N-methyl-D-glucamine ligand groups for arsenic removal. React Funct Polym. 2012;72(9):642-9. https://doi. org/10.1016/j.reactfunctpolym.2012.06.008.

Wang C, Luo H, Zhang Z, Wu Y, Zhang J, Chen S. Removal of As (III) and As (V) from aqueous solutions using nanoscale zero valent iron-reduced graphite oxide modified composites. J Hazard Mater. 2014;268:124-31. https://doi. org/10.1016/j.jhazmat.2014.01.009.

Wang S, Sun H, Ang HM, Tade MO. Adsorptive remediation of environmental pollutants using novel graphene-based nanomaterials. Chem Eng J. 2013;226:336-47.

Weerasundara L, Ok YS, Bundschuh J. Selective removal of arsenic in water: a critical review*. Environ Pollut. 2021;268(Pt B):115668. https://doi.org/10.1016/ j.envpol.2020.115668.

Wu LK, Wu H, Zhang HB, Cao HZ, Hou GY, Tang YP, et al. Graphene oxide/ $\mathrm{CuFe}_{2} \mathrm{O}_{4}$ foam as an efficient absorbent for arsenic removal from water. Chem Eng J. 2018;334:1808-19. https://doi.org/10.1016/j.cej.2017.11.096.

Yin $\mathrm{H}$, Kong M, Gu X, Chen H. Removal of arsenic from water by porous charred granulated attapulgite-supported hydrated iron oxide in bath and column modes. J Clean Prod. 2017;166:88-97. https://doi.org/10.1016/j.jclepro.2017.08.026.

Yoon Y, Park WK, Hwang TM, Yoon DH, Yang WS, Kang JW. Comparative evaluation of magnetite-graphene oxide and magnetite-reduced graphene oxide composite for As(III) and As(V) removal. J Hazard Mater. 2016;304:196204. https://doi.org/10.1016/j.jhazmat.2015.10.053.

Yoon Y, Zheng M, Ahn YT, Park WK, Yang WS, Kang JW. Synthesis of magnetite/nonoxidative graphene composites and their application for arsenic removal. Sep Purif Technol. 2017;178:40-8. https://doi.org/10.1016/j.seppur.2017.01.025.

Zhang K, Dwivedi V, Chi C, Wu J. Graphene oxide/ferric hydroxide composites for efficient arsenate removal from drinking water. J Hazard Mater. 2010;182(1-3): 162-8. https://doi.org/10.1016/j.jhazmat.2010.06.010.

Zheng Q, Hou J, Hartley W, Ren L, Wang M, Tu S, et al. As(III) adsorption on Fe-Mn binary oxides: are Fe and Mn oxides synergistic or antagonistic for arsenic removal? Chem Eng J. 2020;389:124470. https://doi.org/10.1016/j.cej.2020.124470.

Zhu N, Qiao J, Ye Y, Yan T. Synthesis of mesoporous bismuth-impregnated aluminum oxide for arsenic removal: adsorption mechanism study and application to a lab-scale column. J Environ Manage. 2018;211:73-82. https:// doi.org/10.1016/j.jenvman.2018.01.049.

\section{Publisher's Note}

Springer Nature remains neutral with regard to jurisdictional claims in published maps and institutional affiliations. 